\title{
SEGREGACIÓN DE LA FORMACIÓN Y CARRERA DOCENTE Y SU ROL EN LA REPRODUCCIÓN SOCIAL DE LA DESIGUALDAD ${ }^{1}$
}

\author{
Ismael Puga ${ }^{2}$ \\ Diego Polanco 3 \\ Diego Corvalán ${ }^{3}$
}

\section{RESUMEN}

Esta investigación estudia la segregación de la formación y la carrera docente, y su rol en la reproducción social de la desigualdad. Analizamos las relaciones entre el origen socioeconómico del docente y la calidad de sus credenciales en la educación superior con el tipo de dependencia, el nivel socioeconómico y las condiciones laborales del establecimiento donde el docente desempeña su labor. Posteriormente, modelamos el impacto de estas dimensiones con los resultados de los estudiantes en la prueba estandarizada Simce. Se demuestra una fuerte asociación entre el origen social de los docentes con su formación inicial y, por tanto, una importante segregación de la formación docente. Observamos también una fuerte asociación entre el origen social de los docentes y su formación inicial con las características socioeconómicas de la escuela en la que se desempeñan, dando cuenta de la segregación del trabajo docente. Los resultado finales muestran que los puntajes de los estudiantes son fuertemente influenciados por la formación inicial de los docentes y, sobre todo, por las condiciones laborales en que estos trabajan, las que a su vez están en gran parte determinadas por el origen sociales de los profesores. Así, la fuerte segregación de la profesión docente, y el ciclo de asociación entre el origen social de este y el de sus estudiantes, configuran un mecanismo importante de reproducción de la desigualdad social.

Palabras clave: carrera docente, formación docente, segregación escolar, desigualdad educativa, condiciones laborales.

\section{SEGREGATION IN TEACHER PREPARATION AND IN THE TEACHING CAREER, AND ITS ROLE IN THE REPRODUCTION OF SOCIAL INEQUALITIES}

\begin{abstract}
We study the segregation of teacher preparation and the teaching career, and its role in the reproduction of social inequalities. We analyze the relationship between the teachers' social origins and academic credentials, and the type of governance, socioeconomic level and working conditions of the schools where they teach. Then, we model how these different dimensions affect the students' scores on the standardized test Simce. The results show a strong association between the teachers' social origin and credentials, and thus a significant segregation in teacher preparation. We also observe a strong association between the teachers' social origins and academic credentials with the socioeconomic characteristics of the schools where they teach, revealing segregation in the teaching profession. The final results show that students' scores are heavily affected by the teachers' academic preparation, and especially by the working conditions in their schools - which are in turn determined by the teachers' social origins. Thus, the segregation of the teaching career, and the strong association between teachers' and students' social backgrounds, constitute a significant mechanism of the reproduction of social inequality.
\end{abstract}

Keywords: teaching career, teacher training, school segregation, educational inequality, working conditions.

1 Este artículo presenta los resultados finales del proyecto del mismo nombre, realizado para el Consejo Nacional de Educación (CNED). Agradecemos encarecidamente al CNED y al Centro de Estudios de Conflicto y Cohesión Social (CONICYT/FONDAP/15130009), por el apoyo prestado para esta investigación. Agradecemos también a Víctor Orellana, quien enriqueció esta investigación con agudos comentarios y críticas.

2 Escuela de Sociología, Universidad Diego Portales, Santiago, Chile. Contacto: ismael.puga@ mail.udp.cl

3 Sintaxis Consultores, Santiago, Chile. 


\section{Introducción}

El objetivo de este estudio es conocer el grado de segregación social entre los docentes, entendida como una relación sistemática entre la posición socioeconómica de origen de estos, la calidad de sus credenciales y la posición socioeconómica de los estudiantes a quienes enseñan.

La fuerte estratificación social del sistema educativo chileno en sus distintos niveles, desde la educación inicial hasta la educación superior, es ya un hecho estilizado en la literatura. Desde esta observación, resulta esperable que los mismos docentes accedan a una formación y credencialización diferenciada según sus orígenes sociales: si este supuesto se sostiene, la segregación social de los docentes en términos de las instituciones donde enseñan podría contribuir de forma importante a la reproducción de las desigualdades educativas. Si adicionamos a tal panorama la existencia de condiciones de trabajo diferenciadas entre escuelas con más y menos recursos, podemos llegar a describir un complejo sistema de relaciones que contribuye a reforzar la desventaja de los estudiantes provenientes de las clases menos privilegiadas.

Con el fin de evaluar este posible efecto reproductivo, analizamos la relación entre los orígenes sociales de los docentes, su formación inicial y profesional, el tipo de escuelas donde trabajan y las condiciones en las que lo hacen, la posición social de los hogares de sus estudiantes, y el desempeño de estos últimos en pruebas estandarizadas. Con el fin de controlar sesgos bien documentados en la estimación de estos efectos, producidos por el sorting de profesores y estudiantes de acuerdo con habilidades no observadas de los últimos, se utilizarán modelos con efectos fijos basados en el uso de datos de panel de la encuesta longitudinal docente.

\section{Discusión teórica}

\subsection{Educación y reproducción de la desigualdad}

Que la educación formal juega un rol pivote en las sociedades modernas es una idea transversal. Las distintas perspectivas, sin embargo, enfatizan diferentes papeles del sistema educativo en relación 
con el conjunto de la sociedad. Proveer una integración normativa y legitimación, promover la movilidad social y la integración económica, intensificar la productividad y el valor relativo del capital humano, o legitimar diferencias arbitrarias de capital a través de credenciales, son apenas algunas de las funciones, a menudo contradictorias pero no necesariamente excluyentes, que se atribuyen al sistema escolar desde diversas perspectivas.

Proponemos partir de esta idea de funciones contradictorias y no excluyentes. Un sistema educativo puede ser en mayor o menor grado un mecanismo de integración económica, y puede o no favorecer la movilidad social y el valor del trabajo -favoreciendo así la construcción de una sociedad más participativa, integrada e igualitaria-. Al mismo tiempo, un sistema educativo puede sencillamente reproducir y legitimar las diferencias sociales de origen.

En las ciencias sociales, esta confrontación entre dos funciones opuestas del sistema educativo ha tomado forma en distintas posiciones teóricas que disputan el efecto de los sistemas educativos modernos y sus transformaciones en las últimas décadas. Al centro se encuentra la pregunta: ¿qué explica que unos obtengan mejores resultados educativos que otros? Lo que la literatura de orientación a políticas educacionales ha llamado desigualdad de oportunidades educativas (DOE).

Aunque existen diferentes definiciones del concepto de DOE (Coleman, 1975) así como diversas formas de medirlo, en este artículo se adopta la empleada por Breen y Jonsson (2005): hablamos de DOE cuando los factores adscritos determinan el acceso y logro educativos. Los estudios de DOE indagan de qué manera el origen social (OS) de los individuos -esto es, la posición de su hogar de procedencia en distintas operacionalizaciones de las jerarquías sociales-, determina sus "destinos", metas o logros educativos y laborales. Para ello, se indagan las trayectorias de los individuos, analizando el posible efecto causal en tres relaciones básicas: la relación entre el OS y el logro educacional; la relación entre el logro educacional y el logro ocupacional; y la relación directa entre el OS y el logro o destino ocupacional. 
La evidencia empírica internacional es categórica al afirmar que el origen social de los individuos tiende a afectar sus logros en el sistema educativo (Goldthorpe, 2007). Esta literatura, proveniente en su mayoría de países desarrollados (Jackson, 2013; Jackson, Luijkx, Pollak, Vallet, y van de Werfhorst, 2008; Shavit y Blossfeld, 1993), revela que los individuos provenientes de familias con un nivel socioeconómico alto reciben en general "más" y "mejor" educación que aquellos con orígenes socioeconómicos más bajos, incluso en sistemas educativos de alta inversión pública, lo cual les permite tener mejores logros a lo largo de sus trayectorias educativas y laborales y, por lo tanto, alcanzar posiciones sociales más altas (Shavit, Müller y Tame, 1998; Mullen, Goyette y Soares, 2003).

Sin embargo, la evidencia acerca de si la modernización de los sistemas de educación formal contribuye en general a aumentar la movilidad o, por el contrario, a la reproducción de las desigualdades, así como acerca de los alcances y límites de esta reproducción, no es igualmente concluyente. Por una parte, un conjunto de investigaciones desde la aproximación de la "teoría liberal" de la industrialización (Grusky, 1983; Parsons, 1970) señala que, en la medida en que se modernizan y expanden los sistemas educativos, el logro educacional puede contrarrestar las desigualdades asociadas al origen social y así estas tenderían a decrecer en el tiempo. En contraparte, las investigaciones inspiradas en la teoría de la reproducción social (Bourdieu y Passeron, 1977) apuntan a lo contrario: el efecto del OS sobre el logro educacional se mantendría constante, pese al aumento radical de la escolaridad en gran parte del mundo.

Investigaciones recientes desde los principales planteamientos de las teorías de la reproducción (Breen, 1998; Hansen y Mastekaasa, 2006; Kivinen, Ahola y Hedman, 2001; Marks y McMillan, 2003; Zarifa, 2012) han generado nuevas hipótesis para explicar la naturaleza persistente de la desigualdad. Entre ellas, destaca la idea de desigualdad mantenida eficazmente o EMI (Lucas, 2001), que apunta a la relevancia de "desigualdades cualitativas" de acceso a instituciones y programas educativos de prestigio y con mejores condiciones pedagógicas, desigualdades que tenderían a persistir aun cuando se hubiese alcanzado la cobertura universal y las desigualdades 
cuantitativas tendieran a reducirse. Diversos autores han planteado la relevancia de este tipo de desigualdades en Chile en el marco de la expansión de la matrícula (Bernasconi, 2015; Torche, 2005).

El rol de los profesores es, potencialmente, un elemento mayor en la comprensión de estas desigualdades cualitativas en materia educacional. Lo que es más importante, desde la perspectiva de la reproducción, este tipo de desigualdades sería sumamente difícil de identificar con propiedad para los estudiantes y sus hogares, lo que incrementa su potencial para contribuir a la naturalización de la desigualdad. En el lenguaje de Bourdieu, el acceso a docentes mejor preparados (de acuerdo con los estándares de clase con los que los estudiantes serán evaluados una vez fuera del control del docente) y con condiciones laborales más adecuadas puede interpretarse como una fuerza arbitraria de diferencias en capital económico que, sin embargo, se transforman en capital simbólico (Bourdieu 1977, 1979) al acumularse bajo la apariencia de factores "legítimos" como el mérito o la habilidad. Así, la transformación de capital económico en capital cultural (educación, credenciales) se representa negada. Desde el supuesto de que los mecanismos de acceso a niveles superiores de educación (por ejemplo, la Prueba de Selección Universitaria, PSU), así como a posiciones superiores en el mercado laboral, están orientados de acuerdo con criterios de exclusión que favorecen a las clases superiores, la formación por parte de quienes no controlan tales códigos debiera perjudicar el desempeño ulterior en estos campos.

El trabajo de Bourdieu ilumina el potencial impacto de la segregación docente en otro sentido también. El autor postula que la distinción social y la adaptación a los sistemas de medición y asignación de logro no dependen únicamente ni del capital económico ni de habilidades objetivas. Las posiciones sociales de los individuos se "inscriben" en sus cuerpos en la forma de un habitus específico (Bourdieu, 1979): disposiciones heredadas que revelan el origen de los sujetos y les dotan con la capacidad de actuar de modo diferenciado frente a otros y, también, frente a las instituciones que distribuyen las nuevas posiciones sociales. En este marco, los aspectos más sutiles de lo que llamamos capital cultural pueden tener un impacto de proporciones. Más allá de las habilidades estrictamente técnicas de los 
profesores, si los docentes de cierto origen socioeconómico tienden a enseñar a niños de similar estatus, la escuela estará reproduciendo y remarcando la herencia social de estas disposiciones a través del lenguaje, los usos cotidianos, las redes sociales, etc. Si este efecto es relevante, en definitiva, el origen social de los profesores debiera tener un impacto en los logros educativos de los estudiantes (que se miden, diría Bourdieu, de acuerdo con criterios y categorías que benefician el habitus de los más privilegiados), incluso una vez controlado el efecto que la extracción social de los docentes tiene en sus credenciales.

Es importante notar que, al mismo tiempo, el monopolio de la profesión docente por parte de las clases privilegiadas podría representar otro mecanismo igualmente relevante de reproducción y legitimación de las desigualdades sociales. Esta es, en efecto, la principal preocupación de Bourdieu en sus investigaciones acerca del sistema educativo en Francia. Aquí, el docente es el encargado de excluir e incluir, diferencialmente, a sus estudiantes a través de sus evaluaciones y de la práctica pedagógica: es decir, al interior del proceso escolar ${ }^{4}$. En este sentido, si nos encontrarnos realmente con un efecto reproductor de la segregación de la carrera docente, una política pública orientada a la nivelación de oportunidades no puede basarse sencillamente en captar más estudiantes de sectores acomodados para la fuerza de trabajo docente. Siendo la distinción de clase un problema relacional, la única forma de aminorar tal mecanismo reproductor de la desigualdad sería atacar la segregación específicamente: es decir, la asociación entre el origen social de estudiantes y docentes, no la composición de estos últimos.

\subsection{Efecto profesor y sorting}

La literatura internacional presenta extensa evidencia acerca del efecto que tiene un docente en el desarrollo de las habilidades de sus estudiantes. Este efecto es la principal variable explicativa de los logros educacionales de los estudiantes después de su origen socioeconómico y el efecto par (Rivkin, Hanushek y Kain, 2005; Goldhaber y Brewer,

4 Un mecanismo que, conviene aclarar, el presente estudio no puede ni pretende esclarecer. 
1997; Rockoff, 2004). La distribución de los profesores con diferentes características, así como su relación laboral con el establecimiento en el cual se desempeñan, pueden ser importantes factores para explicar las diferencias de desempeño educativo en un sistema.

Sanders y Rivers (1996) reportan que la calidad docente incide en el desempeño escolar más que cualquier otra variable relacionada con la escuela. Estimando diferencias porcentuales en el desempeño de los estudiantes con similar rendimiento inicial como resultado de las diferencias por el efecto no observado de un profesor asignado por tres años, los autores estiman efectos de hasta cincuenta puntos porcentuales. Argumentando que estas diferencias son aditivas en el proceso de aprendizaje y prácticamente irreversibles, los autores concluyen que los efectos de los profesores son acumulativos a través del tiempo.

Similarmente, Rivkin, Hanushek y Kain (2005) utilizan datos administrativos de Texas, EE.UU., para identificar el efecto profesor en el logro educacional de los estudiantes mediante un análisis longitudinal. Sus resultados muestran que las características observables de los profesores tienen efectos pequeños, pero positivos en los logros educacionales de sus estudiantes, no obstante, el efecto no observado tiene un fuerte impacto. Concluyen así que un cambio positivo de 0,1 desviaciones estándar del efecto profesor sería equivalente a reducir el tamaño de la clase en 10 estudiantes en términos de sus logros educativos. Por su parte, Clotfelter, Ladd y Vigdor (2007) encuentran que las credenciales (experiencia, tipo de institución de educación superior que le otorgó su título, etc.) de los docentes se asocian con los logros educativos de los estudiantes, sin embargo, están distribuidas muy desigualmente entre las escuelas.

Para el caso de Chile existen diversos estudios que intentan relacionar el efecto del profesor con el rendimiento de los estudiantes, medido a través de la prueba estandarizada Simce. Para analizar el efecto de la calidad de los docentes, Bravo et al. (2008) usan los resultados de la evaluación docente. Lara, Mizala y Repetto (2011) estudian la misma relación causal agregando las prácticas de aula autorreportadas por los docentes en el cuestionario Simce 
de profesores. La evidencia aportada por ambas investigaciones da cuenta de la importancia, tanto de características observables de los profesores como del contexto en el que trabajan.

Sin embargo, un gran problema para estimar el efecto del profesor en los logros educativos de los estudiantes es el hecho de que estos no son asignados aleatoriamente a quienes les hacen clases, lo que la literatura econométrica denomina sorting. Si los profesores de mejores credenciales son asignados para hacer clases a los estudiantes que tienen mayores habilidades no observadas, por ejemplo, un análisis de corte transversal produciría un sesgo al alza en la estimación del efecto de estas credenciales. En el caso contrario, si se asignaran profesores de mayores credenciales para apoyar el desarrollo académico de los estudiantes menos aventajados, se produciría un sesgo a la baja del mismo efecto (Clotfelter et al., 2007).

Lankford, Loeb y Wyckoff (2002) estudian el sorting de profesores en el estado de Nueva York, tomando características observables de los docentes individuales y evaluando cómo se relacionan estas con atributos de la escuela (índices de selectividad, certificaciones, experiencia, desempeño en pruebas estandarizadas, etc.). Así, los autores dan cuenta de diferencias en la distribución de las características de profesores entre escuelas, mostrando variaciones notables entre establecimientos de zonas urbanas y no urbanas.

Boyd, Lankford, Loeb, Rockoff y Wyckoff (2008) documentan los efectos del sorting entre profesores y estudiantes utilizando una base de datos para el período 2000-2005. Los autores argumentan que medidas que apuntan a la distribución más equitativa de las características de los profesores entre los estudiantes de distintos establecimientos tuvieron como consecuencia una ganancia en los logros educativos de estos, así como también en su acceso a la educación superior.

En Chile ya existe evidencia de que las calificaciones académicas de los profesores están desigualmente distribuidas en establecimientos educacionales que atienden estudiantes de diferentes niveles socioeconómicos, y que estas desigualdades comienzan desde la 
elección de su primer trabajo. Ortúzar, Flores, Milesi y Cox (2009) muestran esta realidad enfocándose en profesores de cuarto básico de escuelas municipales. En tanto, Meckes y Bascopé (2010) encuentran que los estudiantes recién graduados de la carrera Educación Básica que tienen bajas calificaciones en su prueba INICIA y estudiaron en Instituciones de Educación Superior (IES)de baja selectividad, tienen una mayor probabilidad de trabajar en un establecimiento educacional de más bajo nivel socioeconómico.

Toledo, Puentes y Valenzuela (2010) estiman el efecto no observado del profesor en los resultados de sus estudiantes, controlando por la asignación no aleatoria de docentes entre establecimientos educacionales. De esta forma los autores muestran que ciertas características propias del docente (experiencia y avance curricular) afectan permanente y positivamente el desempeño de sus alumnos.

Así, tanto la evidencia internacional como la existente en nuestro país da cuenta de la necesidad de controlar el sorting entre estudiantes y docentes. La literatura sugiere también que el uso de datos longitudinales es la forma más adecuada para enfrentar el problema, metodología que permite además capturar el efecto no observado del profesor (Rockoff, 2004; Rivkin et al., 2005; Clotfelter et al., 2007; Boyd et al., 2008; Toledo et al., 2010).

\section{Metodología}

\subsection{Modelos de análisis}

Para abordar nuestra pregunta central, debemos lidiar con varios objetivos operativos. En primer lugar, identificar y estimar el efecto causal del origen socioeconómico de un docente en el tipo de formación (inicial y profesional) a la que accede. Luego, considerando tanto estos orígenes como la formación del docente, predecir el tipo de escuela (dependencia) donde realizará sus funciones y las condiciones laborales bajo las cuales lo hará. Finalmente, también nos proponemos estimar el efecto causal de sus condiciones laborales, sus orígenes sociales y su formación inicial, en el desempeño académico de los 
estudiantes del establecimiento donde el docente trabaja. A partir de estas estimaciones, será posible describir el siguiente modelo de relaciones causales (aquí simplificado):

Figura 1: Modelo de reproducción social a partir de la segregación docente

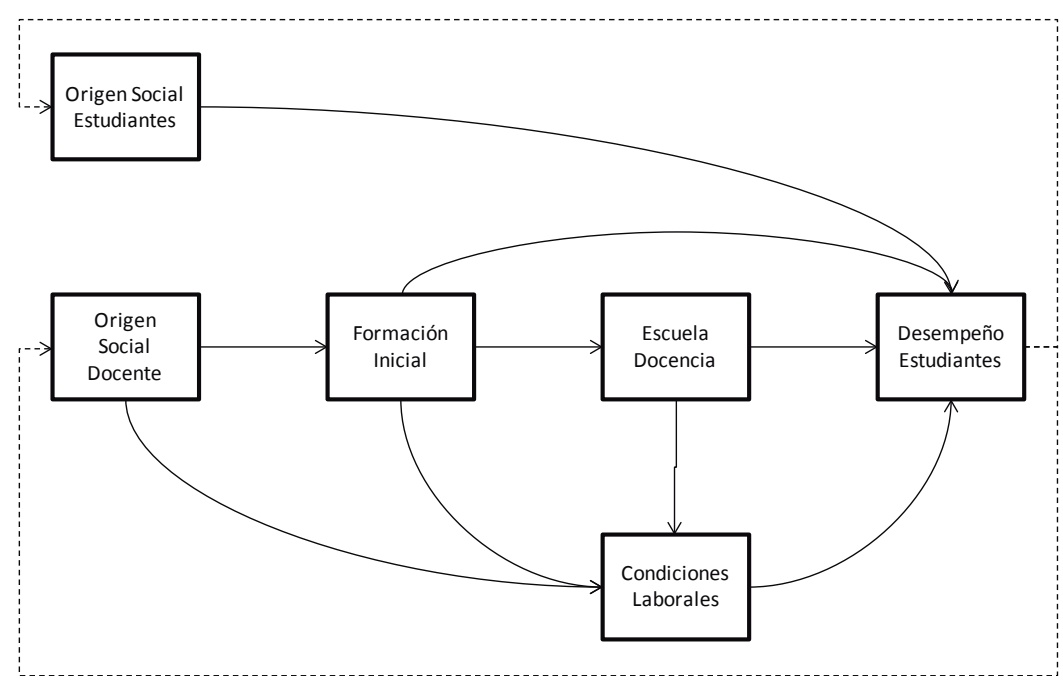

En este modelo, las relaciones a estimar se representan por las flechas completas, mientras que las líneas punteadas muestran las implicaciones teóricas que no podemos estimar actualmente (ya que refieren a la reproducción de las posiciones a futuro de los estudiantes), pero sugieren las implicaciones en materia de transmisión social de la desigualdad que este estudio pretende abordar.

En función de estos objetivos operacionales, en esta investigación consideraremos los siguientes modelos:

$$
\begin{aligned}
& F I_{i}=\alpha_{0}+\alpha_{1} Z_{i}+\varepsilon_{i t} \\
& E^{j}{ }_{i}=\beta_{0}+\beta_{1} F I_{i}+Z_{i}+\mu_{i} \\
& C L_{i}=\gamma_{0}+\gamma_{1} Z_{i}+\gamma_{2} F I_{i}+\gamma_{3} E^{j}{ }_{i}+\eta_{i} \\
& Y_{i t}=\delta_{0}+\delta_{1} X_{i t}+\delta_{2} C L_{i t}+\delta_{3} O_{i}+v_{i t}
\end{aligned}
$$


Donde:

$\mathrm{FI}_{\mathrm{i}}$ es un índice para el profesor ii que será construido a través de un análisis de correspondencias múltiple a partir de la formación escolar y superior (características de los establecimientos) del docente.

$Z_{i}$ es un vector de variables relacionadas con el origen socioeconómico del docente $i i$, tales como la escolaridad de los padres.

$\mathrm{O}_{\mathrm{i}}$ es un vector de variables relacionadas con el origen socioeconómico de los estudiantes que estudian en el establecimiento donde trabaja el docente ii.

$E^{1}{ }_{i}$ es una variable cualitativa relacionada con la dependencia del establecimiento educacional: municipal, particular subvencionada o privado. $E^{2}{ }_{i}$, es una variable cualitativa ordenada que indica el nivel socioeconómico del establecimiento donde se desempeña el docente. $E^{3}{ }_{i}$ es un índice construido a través de un análisis de correspondencia múltiple en el cual colapsa la dimensión de dependencia con la dimensión socioeconómica del establecimiento educacional.

$\mathrm{Y}_{\mathrm{it}}$ es una variable de rendimiento (puntaje Simce promedio del establecimiento) promedio de los estudiantes pertenecientes al establecimiento donde trabaja el profesor $\mathbf{i}$ en el año $\mathbf{t}$.

$\mathrm{X}_{\mathrm{it}}$ es un vector de variables características del profesor $\mathbf{i}$ en el año $\mathbf{t}$ , tales como su nivel educativo (capacitaciones, posgrados, etc), tipo de institución en la cual estudió (tradicional, no tradicional, selectiva, no selectiva).

$\mathrm{CL}_{\mathrm{it}}$ es un índice de precariedad laboral construido a través de un análisis de correspondencias múltiple, indicando las condiciones laborales en las cuales el profesor $\mathbf{i}$ en el año $\mathbf{t}$, desempeña su trabajo.

$\varepsilon_{i t} \mu_{i} \eta_{i} v_{i t}$, son ruido blanco.

Dado que las variables dependientes a estimar en varias de estas funciones corresponden a diferencias cualitativas, se utilizarán modelos logísticos polinomiales para determinar los efectos, así como 
análisis de correspondencias múltiples y de componentes principales para condensar o reducir la información de las categorías involucradas en dimensiones o factores.

De todos estos modelos, el que presenta mayor complejidad para el control de sesgos sistemáticos es el de determinación del desempeño escolar. El uso de una misma distribución en las distintas funciones, cabe recalcar, es una condición para el cálculo final de efectos indirectos en el modelo explicativo agregado.

Como se discutió previamente, el modelo presentado en la ecuación (4) podría presentar un sesgo al alza del efecto de las condiciones laborales y la formación de los profesores en el rendimiento promedio de sus estudiantes de no controlarse el efecto de sorting. Si los establecimientos que entregan mejores condiciones laborales, o reclutan a profesores de mejores credenciales para sus estudiantes mejor rankeados en variables no observadas, estas se correlacionarán positivamente con el puntaje Simce promedio de los establecimientos.

Para enfrentar este problema, utilizaremos el siguiente modelo:

$$
\mathrm{Y}_{\mathrm{it}}=\delta_{0}+\delta_{1} \mathrm{X}_{\mathrm{it}}+\delta_{2} \mathrm{CL}_{\mathrm{it}}+\delta_{3} \mathrm{O}_{\mathrm{i}}+\lambda_{\mathrm{i}}+\mathrm{v}_{\mathrm{it}}
$$

La ecuación (5) describe un modelo en el cual se controla por un efecto $\lambda_{\mathrm{i}}$ a nivel de profesor, con lo cual controlamos por la existencia de habilidades no observables de los profesores.

A partir del total de los modelos estimados, finalmente, será posible inferir la probabilidad de distintas trayectorias docentes para profesores y profesoras de distinto origen social, y el efecto que la segregación de estas trayectorias docentes tendría en la reproducción de las desigualdades educativas en el país.

\subsection{Base de datos}

Consideramos dos unidades de análisis: por un lado el docente, bajo un marco de relaciones con la institución en la que trabaja; y por el otro, a los estudiantes que instruye. Para esto se utiliza la Encuesta 
Longitudinal Docente (ELD), que cuenta con los datos suficientes para estimar los modelos econométricos planteados anteriormente.

La ELD fue realizada por el Centro de Microdatos del Departamento de Economía de la Universidad de Chile, por encargo del Ministerio de Educación del Gobierno de Chile. Es una encuesta de panel, que cuenta con representatividad a nivel nacional, y que entrega la posibilidad de constituir información longitudinal sobre los docentes de Chile.

Su marco muestral corresponde a un total de 168.442 docentes, información obtenida a partir de la base de datos de Idoneidad Docente del Mineduc. Sin embargo, el universo considerado por nuestra investigación incluye únicamente a los profesores de Educación Básica.

El muestreo de la primera ola de la ELD, año 2005, se llevó a cabo en dos etapas. En primer lugar se seleccionaron de manera aleatoria 29 de las 271 comunas de menos de 60.000 habitantes del país: las 71 comunas de más de 60.000 habitantes restantes fueron seleccionadas con probabilidad unitaria. En la segunda etapa se seleccionaron las unidades secundarias de muestreo correspondientes a los docentes. Esto arrojó una muestra con 6.088 observaciones para la ola 2005. Para la segunda ola de la encuesta, tomada el año 2009, se utilizó el mismo método de muestreo, y se amplió la muestra a un conjunto de profesores más jóvenes para ser incluidos en la encuesta, quienes habían ingresado al sistema entre el año 2005 y el 2008. De este modo se agregaron 3.301 docentes no entrevistados en el año 2005 al marco muestral. Del total de 6.088 docentes de la ola 2005, y de los 3.301 nuevos casos, el 2009 se logró entrevistar a 4.663 "Entrevistados 2005" y 1.704 "No entrevistados 2005". Esto significa un porcentaje de cobertura de la encuesta 2009 igual al 76,2\% en el caso de "Entrevistados 2005" y al 75\% para "No entrevistados 2005".

La ELD cuenta con un módulo de formación inicial del docente (FID), donde se detallan datos de su educación básica, media y superior, módulos de perfeccionamiento y capacitación, salud, historia laboral, características del establecimiento principal donde trabaja, 
satisfacción laboral, programas e incentivos, antecedentes familiares, caracterización del hogar del docente. También hay un módulo Simce donde se encuentra el promedio del establecimiento del docente por prueba y el grupo socioeconómico del establecimiento.

Las muestras de los años 2005 y 2009 son diferentes. Si bien mantienen un tronco común, dado que un $76,2 \%$ de los encuestados del 2005 fue nuevamente encuestado en 2009, existe un grupo que solo fue encuestado en alguna de las dos oportunidades. Esto se debe a que la población docente no es invariante en el tiempo, es decir, a la vez que ingresan nuevos profesionales al ejercicio docente, otros se retiran o se jubilan. Por ello, y con la finalidad de utilizar la mayor cantidad posible de información variante en el tiempo, se decidió someter al análisis solo a aquellos que presentan datos respecto del historial laboral y los resultados Simce para cuatro años o más.

Otro recorte necesario en nuestra población objetivo fue considerar solo a aquellos profesores que realizan clases en aula: la base original de la ELD considera a profesores directivos que no hacen clases y/o que no son responsables de dictar algún curso en particular. Dado que el objetivo de la investigación es conocer los efectos que tiene una eventual segregación docente en los logros educativos de los estudiantes, los datos prioritarios para la construcción de la base panel fueron los resultados en la prueba Simce. A partir de los resultados disponibles se fue estructurando el resto de la base de datos.

El trabajo de limpieza y orden en la base de datos permite diferenciar a los profesores según su título de educación superior (Pedagogía General, Básica o Media), la tenencia o no de una mención o especialidad (en particular para los profesores de educación media), el nivel en el que se desempeñan como profesores en su establecimiento principal (básica, media científico humanista o media técnico profesional), el sector en el cual realizan clases (Lenguaje, Matemática, Historia, Ciencias y otros) y los cursos en los cuales hacen clases, entre otras variables de interés.

A partir de ello es posible controlar que solo se evalúe el impacto de los índices de origen social, formación inicial y condiciones 
laborales para los resultados de las pruebas Simce de aquellos cursos en los cuales los profesores hacen clases.

\subsection{Construcción de índices}

Ya tratadas las variables y las observaciones originales de acuerdo con nuestros objetivos de investigación, procedimos a la construcción de tres índices a partir de técnicas multivariadas de reducción de información. Dado el carácter mixto (con información en niveles multinomial, ordinal y de intervalo) de los datos fue necesario combinar diversas técnicas para elaborar índices relevantes. Específicamente, mediante análisis de correspondencias múltiples (MCA) y análisis de componentes principales (PCA).

El primero, MCA o escalamiento óptimo, cuantifica la información presente en variables de carácter cualitativo o categórico, mediante un proceso que implica el uso de tablas de frecuencia de entrada múltiple. Las frecuencias cruzadas de las múltiples categorías, son las que aportan la información necesaria para formar un espacio matemático que expresa similitudes o disimilitudes entre las variables incluidas en el modelo (Greenacre y Blasius, 2006).

El segundo, PCA, pertenece a la familia de los análisis factoriales. Al igual que el MCA su utilidad radica en la capacidad de reducir la información de los datos, facilitando la interpretación, visualización y comprensión de las relaciones, pero en este caso entre variables de carácter cuantitativo. Así, el análisis de componentes principales permite generar nuevas variables (componentes) que puedan expresar en forma resumida la información contenida en el conjunto original de datos, y reducir la dimensionalidad del problema que se está estudiando como paso previo para el uso de modelos predictivos. Los componentes son una combinación lineal de las variables originales, y se ordenan jerárquicamente a partir del porcentaje de varianza original que explican. La solución factorial obtenida puede ser rotada sin alterar sus propiedades fundamentales, lo que permite buscar un conjunto mínimo de factores que contenga la mayor cantidad de varianza posible. 


\subsection{1. Índice de origen social}

Este índice se ha construido utilizando un análisis de correspondencias múltiples (MCA) con las siguientes variables categóricas:

a. Zona Ed. básica: clasificación rural o urbana del establecimiento de educación básica en el que estudió el docente.

b. Dependencia Ed. básica: dependencia del establecimiento de educación básica (municipal, particular subvencionado, particular pagado) en el que estudió el docente.

c. Percepción origen: percepción subjetiva de la situación económica del hogar de origen del docente (muy mala, mala, buena, muy buena).

d. Escolaridad madre: nivel educacional alcanzado por la madre (sin educación, básica, media, superior incompleta, superior completa).

e. Escolaridad padre: nivel educacional alcanzado por el padre (sin educación, básica, media, superior incompleta, superior completa).

El MCA arroja una solución que permite el resumen de la información en un único factor, el que concentra el $62 \%$ de toda la inercia original. Como puede observarse en la Tabla 1 (atendiendo a los puntajes asociados a la dimensión 1), el ordenamiento escalar resultante es conceptualmente consistente. Se asocia a un origen social más bajo la educación en zonas rurales, la educación municipal, una mala percepción de la posición social de origen, y los niveles más bajos de escolaridad de padres y madres. En cambio, se asocia con los orígenes más favorecidos la educación en zonas urbanas, la dependencia particular pagada, una buena percepción de los propios orígenes sociales, y los niveles más altos de educación de padres y madres. Entre las categorías de variables ordinales, el factor obtenido respeta estrictamente su ordinalidad. 
Tabla 1: Solución modelo MCA para el índice de origen social del docente

\begin{tabular}{l|l|c|c|c}
\hline Variable & Categoría & Masa & Coord. Dim 1. & Coord. Dim. 2 \\
\hline \multirow{4}{*}{ Zona Ed. básica } & Urbana & 0,189 & 0,122 & 0,077 \\
\cline { 2 - 5 } $\begin{array}{l}\text { Dependencia } \\
\text { Ed. básica }\end{array}$ & Rural & 0,011 & $-2,015$ & 1,263 \\
\hline \multirow{5}{*}{ Percepción origen } & Municipal & 0,125 & $-0,619$ & 0,066 \\
\cline { 2 - 5 } & Part. Sub. & 0,04 & 0,27 & 0,643 \\
\cline { 2 - 5 } & Part. Pag. & 0,036 & 1,869 & $-0,943$ \\
\hline & Muy mala & 0,004 & $-1,697$ & $-1,686$ \\
\cline { 2 - 5 } & Mala & 0,044 & $-1,268$ & $-0,325$ \\
\cline { 2 - 5 } & Buena & 0,139 & 0,241 & 0,308 \\
\cline { 2 - 5 } & Muy buena & 0,013 & 2,213 & 1,589 \\
\hline \multirow{5}{*}{ Escolaridad madre } & Sin educación & 0,072 & $-1,479$ & $-0,77$ \\
\cline { 2 - 5 } & Básica completa & 0,042 & 0,076 & 1,97 \\
\cline { 2 - 5 } & Media completa & 0,055 & 1,036 & 0,863 \\
\cline { 2 - 5 } & Superior incompleta & 0,012 & 0,575 & $-2,312$ \\
\cline { 2 - 5 } & Superior completa & 0,019 & 2,099 & $-2,446$ \\
\hline \multirow{5}{*}{ Escolaridad padre } & Sin educación & 0,057 & $-1,7$ & $-0,938$ \\
\cline { 2 - 5 } & Básica completa & 0,033 & $-0,174$ & 2,079 \\
\cline { 2 - 5 } & Media completa & 0,057 & 0,734 & 1,279 \\
\cline { 2 - 5 } & Superior incompleta & 0,027 & 0,166 & $-1,345$ \\
\cline { 2 - 5 } & Superior completa & 0,026 & 2,12 & $-2,028$ \\
\hline
\end{tabular}

\subsection{2. Índice de formación inicial}

Este índice se construyó sobre la base de cuatro variables categóricas que describen el tipo de educación media y superior al que accedió el docente, utilizando un modelo de correspondencias múltiples (MCA). Estas variables incluyeron:

a. Tipo de enseñanza media: modalidad de enseñanza media que obtuvo el docente (científico humanista o técnico profesional).

b. Dependencia enseñanza media: dependencia del establecimiento de educación media (municipal, particular subvencionado, particular pagado) en el que estudió el docente.

c. Jornada educación superior: tipo de jornada al que correspondía el programa de educación superior con que el docente adquirió su pregrado (régimen diurno, vespertino, o de solo algunos días). 
d. Nicho educación superior: categorización creada a partir del índice de selectividad y la clasificación histórica de la institución donde el docente obtuvo su pregrado, obteniéndose cuatro categorías (tradicional selectiva, tradicional no selectiva, no tradicional selectiva, no tradicional no selectiva).

La solución alcanzada por el modelo arroja un factor principal que captura también el 62\% de la inercia original, lo que constituye un resultado óptimo para operacionalizar las desigualdades cualitativas en la formación de los docentes en un único factor cuantificado.

Tabla 2: Solución modelo MCA para el índice de formación inicial del docente

\begin{tabular}{l|l|c|c|c}
\hline Variable & Categoría & Masa & Coord. Dim 1. & Coord. Dim. 2 \\
\hline \multirow{2}{*}{$\begin{array}{l}\text { Tipo de Ens. Ed. } \\
\text { media }\end{array}$} & Urbana & 0,21 & 0,49 & 0,10 \\
\cline { 2 - 5 } & Rural & 0,04 & $-2,50$ & $-0,51$ \\
\hline \multirow{3}{*}{$\begin{array}{l}\text { Dependencia Ed. } \\
\text { media }\end{array}$} & Municipal & 0,15 & $-0,34$ & 0,69 \\
\cline { 2 - 5 } & Part. Sub. & 0,06 & $-0,56$ & $-1,53$ \\
\cline { 2 - 5 } & Part. Pag. & 0,04 & 2,11 & $-0,50$ \\
\hline \multirow{3}{*}{$\begin{array}{l}\text { Jornada Ed. } \\
\text { media }\end{array}$} & Diurno & 0,21 & 0,44 & 0,12 \\
\cline { 2 - 5 } & Vespertino & 0,02 & $-1,93$ & $-3,73$ \\
\cline { 2 - 5 } & Algunos días & 0,02 & $-2,98$ & 1,93 \\
\hline \multirow{3}{*}{$\begin{array}{l}\text { Nicho Ed. } \\
\text { superior }\end{array}$} & No tradicional / No selectiva & 0,04 & $-0,48$ & $-2,89$ \\
\cline { 2 - 5 } & Tradicional / No selectiva & 0,09 & $-0,98$ & 1,19 \\
\cline { 2 - 5 } & No tradicional / Selectiva & 0,00 & 0,64 & $-2,40$ \\
\cline { 2 - 5 } & Tradicional / Selectiva & 0,12 & 0,91 & 0,02 \\
\hline
\end{tabular}

Como en el caso anterior, puede observarse en la Tabla 2 que el modelo obtenido captura de modo adecuado la direccionalidad de las diferencias cualitativas. Los puntajes más bajos (en la primera dimensión) se asocian especialmente con una educación media técnico profesional y a una educación superior en instituciones no selectivas. Los puntajes más altos, en cambio, refieren a una educación media en colegios particulares pagados, y a programas diurnos de educación superior en instituciones selectivas - especialmente en las tradicionales-.

La segunda dimensión del modelo es susceptible de interpretación, como un índice de carácter histórico de la formación inicial. Hacia el polo positivo se encuentran los establecimientos 
tradicionales y la dependencia de educación media municipal, posiblemente el tronco histórico de la formación de profesores. Hacia el polo negativo se ubican los establecimientos no tradicionales y la dependencia particular subvencionada y particular pagada. Esta dimensión mostraría la existencia de "dos mundos" que intervienen en la formación de los docentes: uno que posee raigambres vinculadas al Estado (pertenencia al CRUCH y educación municipal), y otro más bien vinculado al nuevo sistema educativo (colegios particulares subvencionados y la apertura de carreras de Pedagogía en universidades no tradicionales). Si bien estos resultados son interesantes, en la medida en que demuestran la existencia de trayectorias consistentes entre ambos mundos a través de los distintos niveles educativos, no juegan un papel importante en el estudio expuesto a continuación -nuestro foco está en diferencias inequívocamente jerárquicas entre las trayectorias educativas de los docentes-.

\subsection{3. Índice de condiciones laborales}

Este índice se construyó utilizando tanto variables estrictamente categóricas, como una variable que se trató como de intervalo: el decil de ingresos por trabajo al que pertenece cada docente dentro del conjunto de la población estudiada, variable a la que se asigna teóricamente una especial relevancia (al representar la principal forma de retribución del trabajo de los profesores). Por lo tanto, la construcción del índice debió elaborarse en dos etapas: en la primera se obtuvo un único factor reflejando la variación latente tras la asociación de las distintas variables categóricas, a partir de un análisis de correspondencias múltiples (MCA); en la segunda, se obtuvo el indicador final a partir de un análisis de componentes principales que integraba el factor resultante de la etapa anterior con la posición relativa del docente en términos de ingresos.

En el primer análisis se consideraron cinco variables categóricas:

a. Sistema de previsión de salud (Fonasa, Isapre, otro)

b. Sistema de pensiones (AFP, Otro, No cotiza).

c. Tipo de contrato (contrato indefinido, a contrata, honorarios).

d. Beneficio de almuerzo: variable binaria indicando si el docente recibe bonificación de alimentación. 
e. Beneficio perfeccionamiento: variable binaria identificando si el docente tiene acceso a incentivos para su perfeccionamiento.

El modelo resultante arroja un factor principal que captura, por sí solo, sobre el 68\% de la inercia original, reteniendo de forma óptima la información en una solución sencilla.

Tabla 3: Solución modelo MCA para el índice de condiciones laborales del docente

\begin{tabular}{|c|c|c|c|c|}
\hline Variable & Categoría & Masa & Coord. Dim 1. & Coord. Dim. 2 \\
\hline \multirow{3}{*}{ Sist. previsión salud } & Fonasa & 0,078 & 1,273 & 0,476 \\
\hline & Isapre & 0,122 & $-0,802$ & $-0,331$ \\
\hline & Otro & 0,000 & $-2,107$ & 8,860 \\
\hline \multirow{3}{*}{ Sist. de pensiones } & AFP & 0,195 & $-0,037$ & $-0,198$ \\
\hline & No cotiza & 0,002 & 2,075 & 13,767 \\
\hline & Otro & 0,004 & 1,152 & 3,967 \\
\hline \multirow{3}{*}{ Tipo de contrato } & Indefinido & 0,167 & $-0,406$ & $-0,127$ \\
\hline & Contrata & 0,031 & 1,959 & $-0,348$ \\
\hline & Honorarios & 0,003 & 3,120 & 12,696 \\
\hline \multirow{2}{*}{ Ben. alimentación } & Sí & 0,031 & $-2,915$ & 1,203 \\
\hline & No & 0,169 & 0,525 & $-0,217$ \\
\hline \multirow{2}{*}{ Ben. perfecc. } & Sí & 0,029 & $-2,997$ & 1,028 \\
\hline & No & 0,171 & 0,510 & $-0,175$ \\
\hline
\end{tabular}

Como podemos observar en la Tabla 3, este factor también refleja de forma adecuada la ordinalidad del problema (aunque el sentido de los puntajes está invertido). Así, los menores puntajes se asocian a la cotización en Isapre y AFP, a contratos indefinidos, al acceso a beneficios básicos como alimentación y a estímulos por el perfeccionamiento. En cambio, los puntajes más altos se asocian a la cotización en Fonasa, a no cotizar para la previsión social, contratos a honorarios y a la ausencia de beneficios.

Tabla 4: Solución modelo PCA para el índice de condiciones laborales del docente

\begin{tabular}{c|c|c|c|c}
\hline \multirow{2}{*}{ Factor } & \multicolumn{2}{|c|}{ Información } & \multicolumn{2}{c}{ Correlaciones } \\
\cline { 2 - 5 } & Autovalor & Varianza & Factor MCA & Decil Ingreso \\
\hline 1 & 1,371 & 0,69 & $-0,707$ & 0,707 \\
\hline 2 & 0,618 & 0,31 & 0,707 & 0,707 \\
\hline
\end{tabular}


En un siguiente paso, integramos el factor resultante del MCA con los deciles de ingreso laboral de los docentes a partir de un análisis de componentes principales. Este análisis, como se observa en la Tabla 4, logra condensar ambas fuentes de información en un único factor que conserva el 69\% de la información original (representando en igual medida tanto el eje de diferencias cualitativas recién obtenido, como la posición relativa en la distribución de ingresos), y arroja puntajes altos para mejores condiciones laborales y bajos para peores condiciones laborales.

\section{Análisis}

\subsection{Estimando el nivel de segregación docente}

Una primera incógnita por resolver es el grado en el que la formación inicial de los docentes en Chile está determinada por sus orígenes sociales. La evidencia empírica respecto del impacto de las posiciones sociales en los logros educativos de los chilenos está fuertemente documentada, pero nos preocupa en este caso la realidad específica de los docentes, quienes comparten, en general, un nivel educativo cuantitativamente similar, pero se educan en un sistema altamente segregado, donde existen importantes desigualdades cualitativas (Torche, 2005).

El modelo simple presentado en la siguiente tabla muestra, como punto de partida, el grado en el que el origen social está determinando la formación inicial de los docentes. La estimación se realiza con una regresión lineal. Como se observa, existe un efecto significativo y muy considerable $(0,357)$ del origen social de los profesores en el acceso a una educación más exclusiva, en instituciones más selectivas. 
Tabla 5: Modelo de regresión lineal (OLS): origen social y formación inicial

\begin{tabular}{l|c}
\hline \multirow{2}{*}{ Origen social } & Mod.1 \\
\cline { 2 - 2 } Constante & $0,357^{* * *}$ \\
\hline $\mathrm{N}$ & $(0,0284)$ \\
\cline { 2 - 2 } & $-0,0843^{* * *}$ \\
\hline R cuadrado & $(0,0290)$ \\
\hline
\end{tabular}

Errores cuadrados entre paréntesis

*** $p<0,01 ;{ }^{* *} p<0,05 ;{ }^{*} p<0,1$

En una segunda etapa, utilizamos un modelo de regresión logística multinomial para explicar la dependencia de la escuela básica donde los profesores de cuarto básico trabajaron entre el año 2004 y 2009. Las variables explicativas incluyen tanto el origen social de los profesores como el tipo de formación inicial que recibieron -que como ya hemos visto, está fuertemente determinado a su vez por el mismo origen social-. Es decir, la formación inicial opera como una mediación entre orígenes sociales y dependencia de la escuela donde se enseña, con lo que nuestro modelo apunta a identificar si existen, adicionalmente a tal mediación, efectos directos del origen social. 
Tabla 6: Modelo de regresión logística multinomial: determinantes de la dependencia de la escuela donde enseña el docente

\begin{tabular}{|c|c|c|c|c|c|c|}
\hline & \multicolumn{3}{|c|}{ Coef. Estimados } & \multicolumn{3}{|c|}{ Efectos Marginales } \\
\hline & $\begin{array}{l}\text { Municipal } \\
\text { (ref) }\end{array}$ & $\begin{array}{c}\text { Part. } \\
\text { Subvenc. }\end{array}$ & $\begin{array}{l}\text { Part. } \\
\text { Pagado }\end{array}$ & $\begin{array}{l}\text { Municipal } \\
\text { (ref) }\end{array}$ & $\begin{array}{c}\text { Part. } \\
\text { Subvenc. }\end{array}$ & $\begin{array}{l}\text { Part. } \\
\text { Pagado }\end{array}$ \\
\hline \multicolumn{7}{|l|}{ Año (ref. 2005) } \\
\hline \multirow{2}{*}{2006} & - & 0,0152 & $-0,0727$ & 0,000976 & 0,00914 & $-0,0101$ \\
\hline & - & $(0,121)$ & $(0,164)$ & $(0,0270)$ & $(0,0272)$ & $(0,0191)$ \\
\hline \multirow{2}{*}{2007} & - & 0,0392 & $-0,0486$ & $-0,00441$ & 0,0131 & $-0,00867$ \\
\hline & - & $(0,125)$ & $(0,168)$ & $(0,0277)$ & $(0,0280)$ & $(0,0196)$ \\
\hline \multirow{2}{*}{2008} & - & 0,110 & $-0,0152$ & $-0,0185$ & 0,0278 & $-0,00927$ \\
\hline & - & $(0,125)$ & $(0,170)$ & $(0,0276)$ & $(0,0280)$ & $(0,0197)$ \\
\hline \multirow{2}{*}{2009} & - & $-0,0376$ & $-0,209$ & 0,0190 & 0,00374 & $-0,0228$ \\
\hline & - & $(0,127)$ & $(0,174)$ & $(0,0285)$ & $(0,0286)$ & $(0,0195)$ \\
\hline \multirow{2}{*}{ Origen social } & & $0,451^{* * *}$ & $1,001^{* * *}$ & $-0,136^{* * *}$ & $0,0430^{* * *}$ & $0,0930^{* * *}$ \\
\hline & & $(0,0430)$ & $(0,0592)$ & $(0,00945)$ & $(0,00940)$ & $(0,00639)$ \\
\hline \multirow{2}{*}{ Formación inicial } & - & $-0,0868 * *$ & $0,548^{* * *}$ & $-0,0143^{*}$ & $-0,0598 * * *$ & $0,0741^{* * *}$ \\
\hline & - & $(0,0370)$ & $(0,0575)$ & $(0,00827)$ & $(0,00850)$ & $(0,00639)$ \\
\hline \multirow{2}{*}{ Constante } & - & $0,226 * *$ & $-0,789 * * *$ & & & \\
\hline & - & $(0,0884)$ & $(0,120)$ & & & \\
\hline N (Observaciones) & 3.349 & 3.349 & 3.349 & 3.349 & 3.349 & 3.349 \\
\hline N (Individuos) & 1.235 & 1.235 & 1.235 & 1.235 & 1.235 & 1.235 \\
\hline
\end{tabular}

Errores cuadrados entre paréntesis.

${ }^{* * *} p<0,01 ;{ }^{* *} p<0,05 ;{ }^{*} p<0,1$.

El modelo se resume en la Tabla 6. Como la dependencia de la escuela donde los profesores ejercen puede variar con el tiempo, hemos incluido como variables de control el año de trabajo al que hace referencia cada observación (opción que hemos mantenido en todos los modelos presentados en adelante). El modelo toma como categoría de referencia, para el cálculo de los coeficientes beta, la categoría de dependencia municipalizada. Si bien son estos coeficientes los que permiten el cálculo de la significación estadística de las relaciones, a efectos de interpretación resultan más útiles las columnas de la derecha: los efectos marginales. Estos valores representan, para nuestros indicadores de interés, el cambio en la probabilidad absoluta de enseñar en escuelas de cada tipo 
de dependencia al aumentar una desviación estándar los factores explicativos.

Los resultados revelan claramente la existencia de efectos significativos y muy marcados del origen social sobre la dependencia del establecimiento donde los docentes se desempeñan. Si consideramos que el rango del índice cubre 4,9 desviaciones estándar en la muestra, hablamos de que un profesor proveniente del límite inferior de las posiciones tiene un $67 \%$ más de probabilidades de enseñar en una escuela municipal que uno cuyo hogar se ubique en el límite opuesto, y un $46 \%$ menos de enseñar en una escuela particular pagada.

Estos efectos son directos, y debemos adicionar a ellos el considerable efecto de la formación inicial. Con un rango de 8,7 desviaciones estándar, este efecto significativo indica que un profesor con la formación inicial más ventajosa tiene un 64\% más de probabilidades de enseñar en un colegio particular pagado que un par con la formación más desventajosa (dentro de nuestra muestra), y un $52 \%$ menos de enseñar en una escuela particular subvencionada.

Aquí observamos, desde ya, que si bien la segregación docente muestra una fuerza considerable, su comportamiento es complejo. Tanto las escuelas municipalizadas como las particular subvencionadas acceden tanto a profesores de origen social más bajo como de credenciales inferiores en comparación con los colegios particulares pagados, pero el primer efecto es mucho más marcado en las escuelas municipales, y en cambio el segundo es mucho más fuerte en las escuelas particulares subvencionadas.

La segregación social de los estudiantes en escuelas de distinto tipo de dependencia en Chile es ya un hecho estilizado en la literatura. Sin embargo, de todas formas es posible ilustrar de modo más directo las implicancias del modelo anterior en términos de la asociación entre el origen social de los docentes y el de sus estudiantes. Con este fin, la Tabla 7 presenta otro modelo logístico multinomial, donde el origen social y formación inicial de los docentes explican la clasificación en el índice de vulnerabilidad económica (en cinco grupos) del principal establecimiento donde trabajan de acuerdo con la base Simce. 
Como antes la dependencia municipal de la escuela, esta vez el modelo tiene en la categoría A, el nivel de mayor vulnerabilidad, como categoría de referencia para el cálculo de los coeficientes de regresión. Y nuevamente, si observamos los efectos marginales de nuestros factores, veremos que el origen social de los docentes tiene fuertes efectos significativos, tanto directos como mediados por su formación inicial. Las probabilidades de enseñar en un colegio del nivel de vulnerabilidad más bajo (los más privilegiados) pueden ser hasta un 66\% mayor para quienes acceden a la formación inicial más exclusiva (en comparación con sus colegas en la situación inversa). Adicionalmente a estos efectos (i.e., para profesores de idéntica formación inicial), claramente estructurados, ya sea por el origen social según nuestro primer análisis, la diferencia por origen social en la probabilidad de enseñar en este tipo de colegios puede ser de hasta un $47 \%$. 


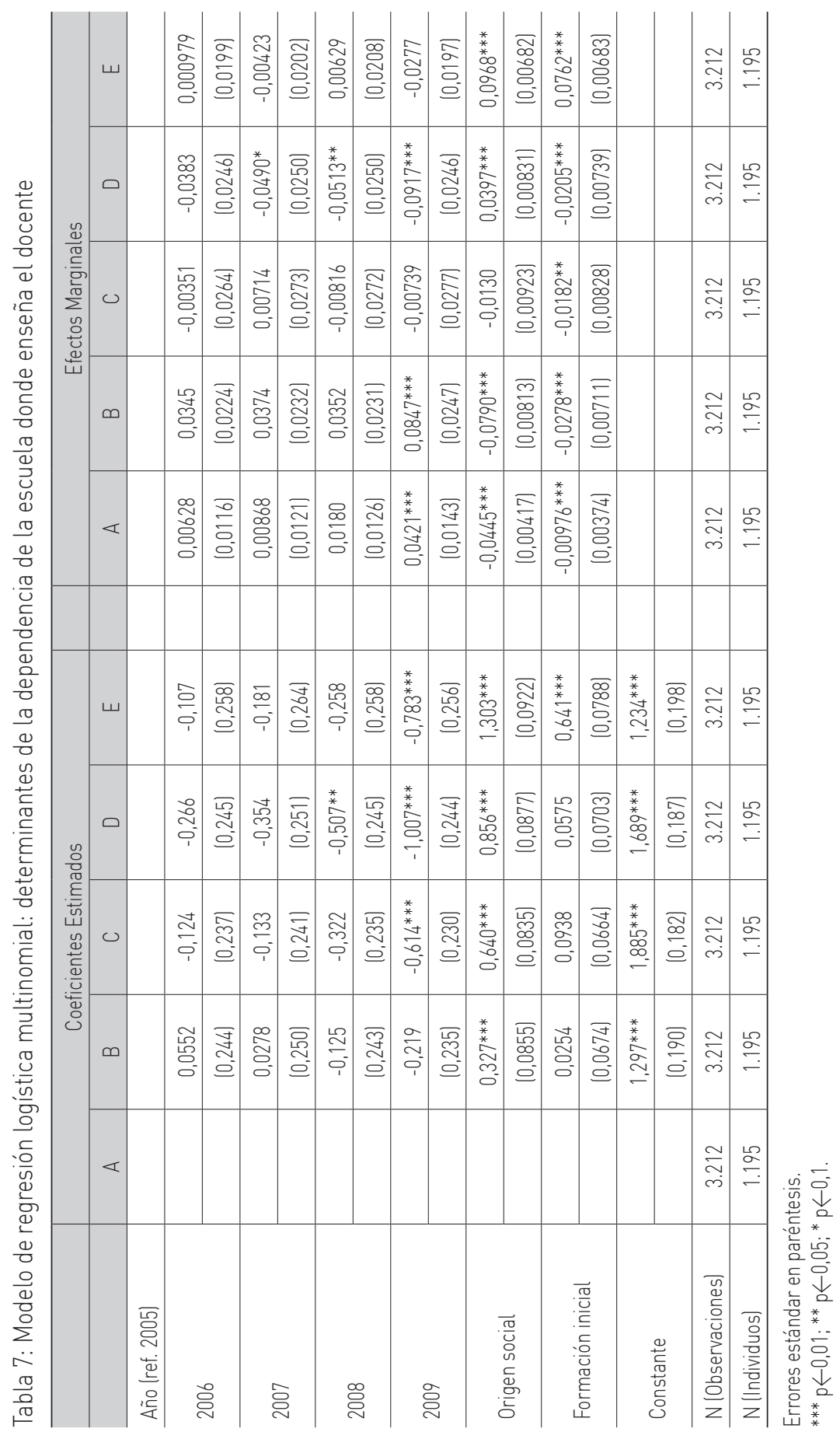


La fuerza y dirección de los hallazgos hasta aquí reportados corroboran, con claridad, la primera intuición detrás de este estudio. En Chile, claramente los profesores provenientes de las clases más bajas enseñan en las escuelas donde acuden los estudiantes de las clases más bajas, mientras que aquellos provenientes de los sectores más privilegiados educan a estos mismos sectores privilegiados.

\subsection{Segregación docente y condiciones laborales}

Hemos establecido, hasta ahora, que el origen social y la formación inicial de los docentes, estrechamente relacionados, condicionan fuertemente el tipo de escuela en la que estos enseñarán y el nivel socioeconómico de sus estudiantes. Si por otro lado consideramos que escuelas con diferentes recursos proporcionarán diferentes condiciones de trabajo a sus docentes, esto tiene fuertes implicancias para los mismos profesores: además de condicionar de modo importante las características, dificultades y ventajas de sus pupilos, una carrera docente segregada puede implicar condiciones de trabajo muy diferentes según el origen social de los profesores.

Con el fin de evaluar esta hipótesis, se han ajustado otros cuatro modelos de regresión lineal que se presentan en la Tabla 8. En este caso, la variable dependiente corresponde al índice de condiciones laborales. Dado la disponibilidad de datos longitudinales en la ELD, se estima un modelo de efectos aleatorios ${ }^{5}$ con el objetivo de controlar por las características no observables del docente que la literatura relaciona al efecto profesor lo cual, en el contexto de las determinantes de las condiciones laborales, pueden ser asociadas a la capacidad individual de cada profesor/a para obtener mejores condiciones laborales.

5 Para efectos de determinar la necesidad de estimar modelos de datos longitudinales de efectos fijos o efectos aleatorios se realizó un test de Hausman, el cual determino que el modelo de efectos aleatorios es preferible por sobre el modelo de efectos fijos en este caso. 
84 SEGREGACIÓN DE LA FORMACIÓN Y CARRERA DOCENTE Y SU ROL EN LA REPRODUCCIÓN SOCIAL DE LA DESIGUALDAD - I. Puga, D. Polanco y D. Corvalán

Tabla 8: Modelos de efectos aleatorios: determinantes del índice de condiciones laborales

\begin{tabular}{|c|c|c|c|c|}
\hline & Mod. 1 & Mod. 2 & Mod. 3 & Mod. 4 \\
\hline \multicolumn{5}{|l|}{ Año (ref. 2005) } \\
\hline \multirow[t]{2}{*}{2006} & $0,0746^{* * *}$ & $0,0536^{*}$ & $0,0561^{*}$ & 0,0457 \\
\hline & $(0,0282)$ & $(0,0303)$ & $(0,0303)$ & $(0,0303)$ \\
\hline \multirow[t]{2}{*}{2007} & $0,175^{* * *}$ & $0,123^{* * *}$ & $0,122^{* * *}$ & $0,117 * *$ \\
\hline & $(0,0288)$ & $(0,0311)$ & $(0,0311)$ & $(0,0311)$ \\
\hline \multirow[t]{2}{*}{2008} & $0,280^{* * *}$ & $0,185^{* * *}$ & $0,180^{* * *}$ & $0,166 * * *$ \\
\hline & $(0,0290)$ & $(0,0322)$ & $(0,0322)$ & $(0,0322)$ \\
\hline \multirow[t]{2}{*}{2009} & $0,391 * * *$ & $0,274^{* * *}$ & $0,276^{* * *}$ & $0,264^{* * *}$ \\
\hline & $(0,0295)$ & $(0,0336)$ & $(0,0334)$ & $(0,0337)$ \\
\hline \multirow[t]{2}{*}{ Origen social } & $0,186^{* * *}$ & $0,0751^{* *}$ & 0,0237 & $-0,0101$ \\
\hline & $(0,0325)$ & $(0,0360)$ & $(0,0346)$ & $(0,0350)$ \\
\hline \multirow[t]{2}{*}{ Formación inicial } & $-0,0298$ & 0,0588 & $-0,00814$ & $-0,0316$ \\
\hline & $(0,0344)$ & $(0,0362)$ & $(0,0351)$ & $(0,0355)$ \\
\hline \multirow[t]{2}{*}{ Experiencia } & & $0,0620 * * *$ & $0,0642^{* * *}$ & $0,0660^{* * *}$ \\
\hline & & $(0,00900)$ & $(0,00876)$ & $(0,00879)$ \\
\hline \multirow[t]{2}{*}{ Experiencia al cuadrado } & & $-0,0009 * * *$ & $-0,0009 * * *$ & $-0,0009 * * *$ \\
\hline & & $(0,000239)$ & $(0,000234)$ & $(0,000235)$ \\
\hline \multicolumn{5}{|c|}{ Dependencia del establecimiento (ref. Municipal) } \\
\hline \multirow{2}{*}{ Particular subvencionado } & & & $0,317^{* * *}$ & $0,259 * * *$ \\
\hline & & & $(0,0551)$ & $(0,0597)$ \\
\hline \multirow[t]{2}{*}{ Particular pagado } & & & $0,759 * * *$ & $0,444^{* * *}$ \\
\hline & & & $(0,0772)$ & $(0,105)$ \\
\hline \multicolumn{5}{|c|}{ Clasificación SE establecimiento (IVE: ref. A) } \\
\hline \multirow[t]{2}{*}{ Grupo B } & & & & $-0,0988$ \\
\hline & & & & $(0,0626)$ \\
\hline \multirow[t]{2}{*}{ Grupo C } & & & & $-0,0797$ \\
\hline & & & & $(0,0729)$ \\
\hline \multirow[t]{2}{*}{ Grupo D } & & & & 0,00824 \\
\hline & & & & $(0,0818)$ \\
\hline \multirow[t]{2}{*}{ Grupo E } & & & & $0,463^{* * *}$ \\
\hline & & & & $(0,109)$ \\
\hline \multirow[t]{2}{*}{ Constante } & $-0,158^{* * *}$ & $-0,807 * * *$ & $-1,134^{* * *}$ & $-1,099 * * *$ \\
\hline & $(0,0384)$ & $(0,0776)$ & $(0,0856)$ & $(0,101)$ \\
\hline $\mathrm{N}$ (Observaciones) & 2.753 & 2.516 & 2.515 & 2.403 \\
\hline$N$ (Individuos) & 1.081 & 995 & 995 & 963 \\
\hline
\end{tabular}

Errores estándar en paréntesis.

${ }^{* * *} p<0,01 ;{ }^{* *} p<0,05 ;{ }^{*} p<0,1$. 
El primer modelo de la tabla incluye los indicadores de origen social y el índice de formación inicial, considerando únicamente el año de observación como variable de control. Ya en este modelo podemos observar un problema interesante: mientras que una mejor formación inicial no implica para los docentes el acceso a mejores condiciones de trabajo, sí ocurre así con su origen social. Es decir, entre dos profesores con idéntica formación inicial, el profesor cuyo hogar de origen posea mayor estatus socioeconómico accederá tendencialmente a un empleo con mayor estabilidad y remuneración económica. En cambio, entre dos profesores con orígenes sociales equivalentes, una mejor formación inicial no estaría indicando mejorías laborales significativas.

El segundo modelo ingresa, como variable de control, la experiencia laboral de los docentes. La experiencia, de acuerdo con los hallazgos previos de la literatura, se ingresa como factor tanto en forma lineal como exponencial. El objetivo del modelo es comprobar que la relación entre el origen social y las condiciones laborales no sea espuria, respondiendo en realidad a una experiencia laboral diferenciada (por ejemplo, la que puede producir una reducción histórica de la extracción social del profesorado). Si bien introducir este control reduce la magnitud del efecto del origen social, este sigue siendo claramente significativo. Es decir, la relación entre el origen social y las condiciones laborales es robusta: no puede descartarse como un efecto de cohorte.

Los modelos tres y cuatro de la tabla introducen, respectivamente, la dependencia y la clasificación de vulnerabilidad económica de las escuelas como factores en la ecuación. Ya al ingresar la dependencia, podemos observar que el efecto del origen social en las condiciones laborales se desvanece. Esto no significa, sin embargo, que el efecto del origen social sea espurio. Muy por el contrario, concluimos que tal efecto está mediado por la dependencia de las escuelas en las que los docentes acceden al trabajo, sistemáticamente estructurada (como hemos analizado previamente) por su mismo origen social. Los docentes de distintas clases sociales de origen acceden a distintas condiciones laborales, principalmente porque ingresan a escuelas de distinta dependencia y nivel socioeconómico. De haber encontrado 
un efecto significativo incluso con estos controles, habríamos de concluir que el origen social modifica las condiciones laborales del docente significativamente incluso dentro de escuelas de dependencia y vulnerabilidad similar.

\subsection{Segregación docente y logro escolar}

Hasta aquí, hemos establecido claramente cuatro grandes relaciones. La primera es una especificación, para el mundo de la formación docente, de un hallazgo ya estilizado en la literatura empírica acerca de la educación en Chile. Los profesores de distinto origen social acceden, sistemáticamente, a una formación inicial (secundaria y superior) de distinta calidad: aquellos provenientes de hogares con menos recursos, son formados por instituciones muy diferentes a las que forman a aquellos provenientes de hogares más aventajados.

En segundo lugar, hemos establecido que efectivamente los profesores de educación básica de distinto origen social, y por lo tanto con distintas trayectorias de formación inicial, enseñan en escuelas muy diferentes. Los docentes de posición social de origen más alto, y aquellos formados en escuelas y universidades más caras y/o selectivas, tienden a enseñar con mayor frecuencia en escuelas particulares pagadas. En cambio, los profesores con orígenes sociales menos privilegiados, y que accedieron a trayectorias educativas de menor costo y calidad, tienden a enseñar con mayor frecuencia en las escuelas municipales. De igual modo, la posición social de origen de los profesores se asocia fuertemente con el nivel socioeconómico de sus estudiantes: los profesores que provienen de hogares con menores recursos, y con una formación inicial menos privilegiada, tienden a enseñar en las escuelas cuyos estudiantes tienen también menos recursos, mientras que lo contrario ocurre con aquellos docentes provenientes de la cota superior en términos socioeconómicos ${ }^{6}$. Es decir, y esto es un hallazgo central para el estudio presente, efectivamente encontramos un fuerte efecto de segregación docente.

6 Por cierto, debe notarse que estas concurrencias son relativas, en el sentido de que el origen social de la población de profesores no tiene exactamente la misma distribución que el origen social de los estudiantes de educación básica. 
En tercer lugar, y de acuerdo con nuestras especulaciones iniciales, encontramos que la segregación de la población docente se asocia a condiciones laborales claramente diferenciadas. Los profesores provenientes de clases más bajas tienden a enseñar más en escuelas públicas y, dentro de las distintas dependencias institucionales, a estudiantes de nivel socioeconómico más bajo: estos destinos laborales segregados implican que estos profesores acceden, finalmente, a empleos con peores condiciones laborales.

Hemos descrito, en resumen, todo un proceso de segregación de la carrera docente de acuerdo con los atributos adscritos de los profesores. Resta evaluar, finalmente, si es que todo este entramado de relaciones contribuye a la generación de resultados escolares diferenciados entre los estudiantes de distinto origen socioeconómico. Para esto, analizaremos cómo se relaciona el origen social de los profesores, y el conjunto de variables que hemos considerado en nuestro modelo, con los resultados de los estudiantes en distintas áreas. Con este fin, las Tablas 9, 10, y 11 presentan una serie de modelos de panel cuya variable dependiente es, respectivamente, el desempeño de los estudiantes en Lenguaje, Matemática y Comprensión del entorno. Para efectos de controlar por el efecto profesor y el sorting, se estiman modelos de efectos aleatorios cómo se plantea en la ecuación (5). ${ }^{7}$

7 Para los modelos correspondientes a las determinantes del desempeño SIMCE también se realizan test de Hausman, los cuales determinan la preferencia de un modelo de efectos aleatorios por sobre un modelo de efectos fijos en los tres casos. 
88 SEGREGACIÓN DE LA FORMACIÓN Y CARRERA DOCENTE Y SU ROL EN LA REPRODUCCIÓN SOCIAL DE LA DESIGUALDAD - I. Puga, D. Polanco y D. Corvalán

Tabla 9: Modelos de efectos aleatorios: determinantes del desempeño Simce Lenguaje

\begin{tabular}{|c|c|c|c|c|}
\hline & Mod. 1 & Mod. 2 & Mod. 3 & Mod. 4 \\
\hline \multicolumn{5}{|l|}{ Año (ref. 2005) } \\
\hline \multirow{2}{*}{2006} & $-3,884^{* * *}$ & $-3,611 * * *$ & $-3,189 * * *$ & $-2,905 * * *$ \\
\hline & $(0,982)$ & $(1,061)$ & $(1,009)$ & $(0,948)$ \\
\hline \multirow{2}{*}{2007} & $-3,199 * * *$ & $-2,603 * *$ & $-2,153^{* *}$ & $-0,833$ \\
\hline & $(1,006)$ & $(1,082)$ & $(1,026)$ & $(0,964)$ \\
\hline \multirow{2}{*}{2008} & 1,198 & $2,322^{* *}$ & $2,773^{* * *}$ & $3,864^{* * *}$ \\
\hline & $(1,018)$ & $(1,103)$ & $(1,041)$ & $(0,972)$ \\
\hline \multirow{2}{*}{2009} & $-0,434$ & 0,707 & $1,852^{*}$ & $4,654^{* * *}$ \\
\hline & $(1,045)$ & $(1,138)$ & $(1,067)$ & $(0,994)$ \\
\hline \multirow{2}{*}{ Origen social } & $7,004^{* * *}$ & $5,318^{* * *}$ & $1,851^{* *}$ & $-0,158$ \\
\hline & $(0,798)$ & $(0,883)$ & $(0,745)$ & $(0,595)$ \\
\hline \multirow{2}{*}{ Formación inicial } & $3,141^{* * *}$ & $5,032^{* * *}$ & $1,788^{* *}$ & $1,307 * *$ \\
\hline & $(0,754)$ & $(0,873)$ & $(0,736)$ & $(0,584)$ \\
\hline \multirow{2}{*}{ Condiciones laborales } & $5,714^{* * *}$ & $6,312^{* * *}$ & $3,039 * * *$ & $1,836^{* * *}$ \\
\hline & $(0,548)$ & $(0,591)$ & $(0,540)$ & $(0,461)$ \\
\hline \multirow{2}{*}{ Experiencia } & & $-0,126$ & 0,269 & 0,217 \\
\hline & & $(0,251)$ & $(0,216)$ & $(0,177)$ \\
\hline \multirow{2}{*}{ Experiencia al cuadrado } & & $-0,00447$ & $-0,00620$ & $-0,00493$ \\
\hline & & $(0,00679)$ & $(0,00583)$ & $(0,00480)$ \\
\hline \multicolumn{5}{|c|}{ Depen. del establecimiento (ref. Municipal) } \\
\hline \multirow{2}{*}{ Particular subvencionado } & & & $19,68^{* * *}$ & $5,389 * * *$ \\
\hline & & & $(1,352)$ & $(1,274)$ \\
\hline \multirow{2}{*}{ Particular pagado } & & & $44,79 * * *$ & $8,124^{* * *}$ \\
\hline & & & $(1,972)$ & $(2,517)$ \\
\hline \multicolumn{5}{|c|}{ Clasificación SE establecimiento (IVE: ref. A) } \\
\hline \multirow{2}{*}{ Grupo B } & & & & 2,832 \\
\hline & & & & $(1,864)$ \\
\hline \multirow{2}{*}{ Grupo C } & & & & $17,31^{* * *}$ \\
\hline & & & & $(1,984)$ \\
\hline \multirow{2}{*}{ Grupo D } & & & & $35,39 * * *$ \\
\hline & & & & $(2,167)$ \\
\hline \multirow{2}{*}{ Grupo E } & & & & $52,86^{* * *}$ \\
\hline & & & & $(2,889)$ \\
\hline \multirow{2}{*}{ Constante } & $265,6^{* * *}$ & $269,2^{* * *}$ & $246,1^{* * *}$ & $234,8^{* * *}$ \\
\hline & $(1,011)$ & $(2,111)$ & $(2,132)$ & $(2,396)$ \\
\hline N (Observaciones) & 2.534 & 2.314 & 2.313 & 2.313 \\
\hline $\mathrm{N}$ (Individuos) & 1.026 & 945 & 945 & 945 \\
\hline
\end{tabular}

Errores estándar en paréntesis.

${ }^{* * *} p<0,01 ;{ }^{* *} p<0,05 ;{ }^{*} p<0,1$. 
Observando la Tabla 9, veremos en el primer modelo tres importantes efectos significativos: el de formación inicial, condiciones laborales y de origen social. Cabe detenerse a examinar las implicancias de estos tres efectos.

Como comprobamos anteriormente, la formación inicial de los docentes está fuertemente estructurada por sus orígenes sociales. Los profesores que provienen de hogares menos privilegiados acceden a instituciones y programas diferentes de los que educan a los profesores de mayor estatus socioeconómico de origen. Es decir, el efecto de la formación inicial del docente sobre el logro educativo de los estudiantes no es autónomo del efecto de la segregación docente: por el contrario, se trata de una mediación. Existe un efecto indirecto entre el origen social de los docentes y los resultados de los estudiantes en el área de Lenguaje, que pasa por la formación inicial a la que acceden los docentes.

El caso de las condiciones laborales es muy similar. Como la formación inicial, las condiciones laborales no son independientes del origen social de los docentes. El fuerte efecto de estas condiciones sobre los resultados académicos en el área de Lenguaje de los estudiantes, no puede separarse del origen social de los docentes. Así como la formación inicial, este efecto de las condiciones laborales representa una importante mediación a través de la cual la segregación docente (la asociación entre la posición social de origen de docentes y estudiantes) estaría afectando los resultados educativos, potenciando la reproducción de la desigualdad.

Finalmente, existe además un efecto directo del origen social de los docentes sobre los logros en Lenguaje de los estudiantes. Es decir, además del efecto mediado por las condiciones laborales, y del efecto mediado por formaciones iniciales diferenciadas, la asociación entre orígenes sociales de docentes y estudiantes está reforzando la desigualdad educativa mediante otros efectos cuyos mecanismos no están siendo observados directamente: mecanismos que, podemos especular, podrían rastrearse hasta el capital cultural de los docentes.

El segundo modelo en la tabla tiene el objetivo de evaluar los efectos antes analizados de forma robusta, controlando por el efecto 
de la experiencia laboral de los docentes. Como explicamos en el apartado anterior, omitir este factor podría sesgar la estimación de los efectos del origen social en la medida en que exista una tendencia histórica al reclutamiento de profesores de mayor o menor estatus de origen a través del tiempo. Contra lo esperado, sin embargo, la experiencia (ingresada lineal y exponencialmente) no arroja efectos significativos sobre el logro en Lenguaje. La ausencia de este efecto, puede especularse, podría deberse a la existencia de dos efectos opuestos que se confunden: un efecto positivo de la experiencia en sí, y otro efecto negativo de la actualización de la formación docente en relación con el currículo escolar. En cualquier caso, representa una interrogante de investigación interesante. 
Tabla 10: Modelos de efectos aleatorios: determinantes del desempeño Simce. Comp. del Medio

\begin{tabular}{|c|c|c|c|c|}
\hline & Mod. 1 & Mod. 2 & Mod. 3 & Mod. 4 \\
\hline \multicolumn{5}{|l|}{ Año (ref. 2005) } \\
\hline \multirow{2}{*}{2006} & $-0,936$ & $-0,881$ & $-0,467$ & $-0,150$ \\
\hline & $(0,958)$ & $(1,039)$ & $(0,980)$ & $(0,913)$ \\
\hline \multirow{2}{*}{2007} & $-9,061^{* * *}$ & $-8,317^{* * *}$ & $-7,833^{* * *}$ & $-6,292^{* * *}$ \\
\hline & $(0,983)$ & $(1,062)$ & $(0,999)$ & $(0,929)$ \\
\hline \multirow{2}{*}{2008} & $-10,91^{* * *}$ & $-9,730 * * *$ & $-9,347^{* * *}$ & $-8,082^{* * *}$ \\
\hline & $(0,996)$ & $(1,087)$ & $(1,015)$ & $(0,937)$ \\
\hline \multirow{2}{*}{2009} & $-7,467 * * *$ & $-5,966 * * *$ & $-4,834^{* * *}$ & $-1,760^{*}$ \\
\hline & $(1,025)$ & $(1,126)$ & $(1,044)$ & $(0,959)$ \\
\hline \multirow{2}{*}{ Origen social } & $7,498 * * *$ & $5,407^{* * *}$ & $1,564^{* *}$ & $-0,685$ \\
\hline & $(0,859)$ & $(0,947)$ & $(0,776)$ & $(0,587)$ \\
\hline \multirow{2}{*}{ Formación inicial } & $3,070^{* * *}$ & $5,256^{* * *}$ & $1,710^{* *}$ & $1,155^{* *}$ \\
\hline & $(0,813)$ & $(0,938)$ & $(0,767)$ & $(0,577)$ \\
\hline \multirow{2}{*}{ Condiciones laborales } & $5,682^{* * *}$ & $6,402^{* * *}$ & $2,949 * * *$ & $1,694^{* * *}$ \\
\hline & $(0,566)$ & $(0,609)$ & $(0,547)$ & $(0,451)$ \\
\hline \multirow{2}{*}{ Experiencia } & & $-0,153$ & 0,277 & 0,218 \\
\hline & & $(0,263)$ & $(0,221)$ & $(0,174)$ \\
\hline \multirow{2}{*}{ Experiencia al cuadrado } & & $-0,00678$ & $-0,00842$ & $-0,00693$ \\
\hline & & $(0,00706)$ & $(0,00596)$ & $(0,00471)$ \\
\hline \multicolumn{5}{|c|}{ Dependencia del establecimiento (ref. Municipal) } \\
\hline \multirow{2}{*}{ Particular subvencionado } & & & $22,78 * * *$ & $6,944^{* * *}$ \\
\hline & & & $(1,381)$ & $(1,249)$ \\
\hline \multirow{2}{*}{ Particular pagado } & & & $49,78^{* * *}$ & $10,65^{* * *}$ \\
\hline & & & $(2,019)$ & $(2,456)$ \\
\hline \multicolumn{5}{|c|}{ Clasificación SE establecimiento (IVE: ref. A) } \\
\hline \multirow{2}{*}{ Grupo B } & & & & $6,673^{* * *}$ \\
\hline & & & & $(1,805)$ \\
\hline \multirow{2}{*}{ Grupo C } & & & & $22,55^{* * *}$ \\
\hline & & & & $(1,926)$ \\
\hline \multirow{2}{*}{ Grupo D } & & & & $42,34^{* * *}$ \\
\hline & & & & $(2,107)$ \\
\hline \multirow{2}{*}{ Grupo E } & & & & $60,13^{* * *}$ \\
\hline & & & & $(2,809)$ \\
\hline \multirow[t]{2}{*}{ Constante } & $267,7^{* * *}$ & $272,8^{* * *}$ & $246,9 * * *$ & $231,3^{* * *}$ \\
\hline & $(1,048)$ & $(2,211)$ & $(2,178)$ & $(2,333)$ \\
\hline N (Observaciones) & 2.532 & 2.312 & 2.311 & 2.311 \\
\hline $\mathrm{N}$ (Individuos) & 1.025 & 944 & 944 & 944 \\
\hline
\end{tabular}

Errores estándar en paréntesis.

${ }^{* * *} p<0,01 ;{ }^{* *} p<0,05 ;{ }^{*} p<0,1$. 
Sin embargo, en lo que respecta a los objetivos de nuestra investigación, el hallazgo central es el siguiente: al ingresar como control la experiencia de los docentes, todos los efectos antes descritos continúan siendo significativos. Se trata de efectos robustos, que no pueden atribuirse a la asociación entre cualquiera de las variables explicativas con la experiencia docente.

El tercer modelo incorpora como variable explicativa la dependencia de las escuelas. Es decir, sin cuestionar de por sí el efecto de la segregación docente, nos permite evaluar si tal efecto se produce inclusive al interior de escuelas de la misma dependencia. Observamos, en esta columna, que los tres efectos de interés continúan siendo significativos: es decir, el origen social de los docentes, y por lo tanto la segregación de la carrera docente como fenómeno agregado, afecta el desempeño escolar de los estudiantes (en el área de Lenguaje) incluso entre escuelas de dependencia similar (que tienden a contratar profesores, hemos observado, de origen social más homogéneo). Como colofón, no encontramos indicios de que ninguno de estos efectos pueda reducirse, en ningún caso, a efectos de nivel institucional que pudieran estar sesgando nuestras estimaciones.

Finalmente, el cuarto modelo incorpora la clasificación socioeconómica de las escuelas. Al agregarse a la dependencia del establecimiento, evaluar efectos en este nivel equivale a corroborar la hipótesis de que, al interior de las escuelas de igual dependencia y similar condición socioeconómica, los efectos siguen siendo relevantes. En este modelo, el efecto directo del origen social se difumina, pero continúan siendo claramente significativos los efectos mediadores de la formación inicial y las condiciones laborales. Es decir, el efecto directo que hasta entonces observábamos entre el origen social del docente y los resultados en Lenguaje, no puede separarse de los orígenes de sus estudiantes (y por tanto, de sus propias condiciones materiales y su capital cultural heredado). Sin embargo, las desigualdades cualitativas en términos de formación inicial de los docentes, así como las desigualdades en términos de sus condiciones laborales, sí continúan afectando el desempeño en Lenguaje de los estudiantes en escuelas de dependencia y situación económica similar. Estas desigualdades, hemos mostrado, están estructuradas por el origen social de los docentes y, a su vez, por el origen social de los estudiantes. 
Es decir, corresponden a mecanismos mediante los que la segregación de la carrera docente contribuye a la reproducción de desigualdades educativas entre los alumnos de distinta posición socioeconómica.

Tabla 11: Modelos de efectos aleatorios: determinantes del desempeño Simce Matemática

\begin{tabular}{|c|c|c|c|c|}
\hline & Mod. 1 & Mod. 2 & Mod. 3 & Mod. 4 \\
\hline \multicolumn{5}{|l|}{ Año (ref. 2005) } \\
\hline \multirow{2}{*}{2006} & $-1,111$ & $-0,672$ & $-0,175$ & 0,140 \\
\hline & $(1,090)$ & $(1,176)$ & $(1,112)$ & $(1,035)$ \\
\hline \multirow{2}{*}{2007} & $-2,386^{* *}$ & $-1,370$ & $-0,784$ & 0,785 \\
\hline & $(1,117)$ & $(1,199)$ & $(1,132)$ & $(1,053)$ \\
\hline \multirow{2}{*}{2008} & $-2,910^{* *}$ & $-1,333$ & $-0,832$ & 0,413 \\
\hline & $(1,132)$ & $(1,225)$ & $(1,150)$ & $(1,063)$ \\
\hline \multirow{2}{*}{2009} & $-0,252$ & 1,247 & $2,550 * *$ & $5,751^{* * *}$ \\
\hline & $(1,164)$ & $(1,267)$ & $(1,182)$ & $(1,089)$ \\
\hline \multirow{2}{*}{ Origen social } & $8,075^{* * *}$ & $6,146^{* * *}$ & $2,047 * *$ & $-0,355$ \\
\hline & $(0,917)$ & $(1,018)$ & $(0,850)$ & $(0,669)$ \\
\hline \multirow{2}{*}{ Formación inicial } & $3,412^{* * *}$ & $5,464^{* * *}$ & $1,642^{*}$ & 1,041 \\
\hline & $(0,867)$ & $(1,008)$ & $(0,841)$ & $(0,656)$ \\
\hline \multirow{2}{*}{ Condiciones laborales } & $6,372^{* * *}$ & $6,902^{* * *}$ & $3,178^{* * *}$ & $1,878^{* * *}$ \\
\hline & $(0,621)$ & $(0,670)$ & $(0,608)$ & $(0,513)$ \\
\hline \multirow{2}{*}{ Experiencia } & & $-0,0153$ & 0,399 & 0,313 \\
\hline & & $(0,287)$ & $(0,244)$ & $(0,198)$ \\
\hline \multirow{2}{*}{ Experiencia al cuadrado } & & $-0,00883$ & $-0,00974$ & $-0,00759$ \\
\hline & & $(0,00772)$ & $(0,00659)$ & $(0,00536)$ \\
\hline \multicolumn{5}{|c|}{ Dependencia del establecimiento (ref. Municipal) } \\
\hline \multirow{2}{*}{ Particular subvencionado } & & & $22,20^{* * *}$ & $5,385^{* * *}$ \\
\hline & & & $(1,529)$ & $(1,420)$ \\
\hline \multirow{2}{*}{ Particular pagado } & & & $53,03 * * *$ & $9,675^{* * *}$ \\
\hline & & & $(2,233)$ & $(2,792)$ \\
\hline \multicolumn{5}{|c|}{ Clasificación SE establecimiento (IVE: ref. A) } \\
\hline \multirow{2}{*}{ Grupo B } & & & & $8,326 * * *$ \\
\hline & & & & $(2,048)$ \\
\hline \multirow{2}{*}{ Grupo C } & & & & $23,64 * * *$ \\
\hline & & & & $(2,186)$ \\
\hline \multirow{2}{*}{ Grupo D } & & & & $45,04^{* * *}$ \\
\hline & & & & $(2,392)$ \\
\hline \multirow{2}{*}{ Grupo E } & & & & $66,31 * * *$ \\
\hline & & & & $(3,190)$ \\
\hline \multirow[t]{2}{*}{ Constante } & $258,0^{* * *}$ & $261,3^{* * *}$ & $235,0^{* * *}$ & $218,2^{* * *}$ \\
\hline & $(1,146)$ & $(2,409)$ & $(2,410)$ & $(2,651)$ \\
\hline N (Observaciones) & 2.532 & 2.312 & 2.311 & 2.311 \\
\hline$N$ (Individuos) & 1.025 & 944 & 944 & 944 \\
\hline
\end{tabular}

Errores estándar en paréntesis.

${ }^{* * *} p<0,01 ;{ }^{* *} p<0,05 ;{ }^{*} p<0,1$. 
Con diferencias numéricas menores, la Tabla 10 muestra un patrón de efectos significativos y no significativos equivalente para el desempeño de los estudiantes en el área de Comprensión del Medio. Inicialmente observamos tres efectos significativos: formación inicial, condiciones laborales y efecto directo del origen social, efectos que se mantienen al controlar por experiencia docente y dependencia de los establecimientos. Sin embargo, el efecto directo del origen social pierde su significación estadística cuando se introduce el control por clasificación de vulnerabilidad de las escuelas.

La Tabla 11 muestra, también, un patrón muy similar para el área de Matemática. La diferencia central está en que la formación inicial, al igual que el efecto directo de los orígenes sociales del docente, pierde su significación en el último modelo. Esto podría sugerir que, al estar menos mediado por el Lenguaje y más formalizado (siendo el lenguaje un ámbito especialmente relevante para la transmisión de códigos diferenciados de clase), la reproducción de las desigualdades educativas es marginalmente menor en el área de Matemática. Sin embargo, eso queda claramente en el ámbito de la especulación teórica por el momento, y sin duda trasciende los fines explicativos del presente estudio. Lo central es, respecto de nuestros objetivos, que los resultados en términos de efectos sobre el desempeño escolar son remarcablemente estables entre distintas áreas del conocimiento que, a efectos de nuestra investigación, pueden entenderse como distintas mediciones de un factor latente común (logro educativo). Es decir, observamos efectos considerablemente robustos, que nos permiten obtener conclusiones bastante confiables acerca de la existencia una segregación docente que posee un efecto reproductor de la desigualdad entre los estudiantes chilenos.

\section{Discusión y conclusiones}

Los resultados hasta aquí presentados hablan de una fuerte segregación social de la carrera docente, cuyos efectos en la desigualdad de resultados educativos es considerable. Si bien la necesidad de utilizar distintos tipos de regresión (debido a los distintos niveles de medición involucrados en las variables dependientes), merma nuestra capacidad de calcular efectos totales, sí podemos establecer 
mecanismos explicativos mediante los que el origen social de los docentes estaría afectando los resultados escolares. Al respecto, cabe considerar cuidadosamente la siguiente tabla que identifica los efectos significativos encontrados.

Tabla 12: Resumen de efectos significativos estimados

\begin{tabular}{l|c|c|c|c|c}
\hline $\begin{array}{l}\text { Efectos directos } \\
\text { ladicionales a } \\
\text { los otros efectos } \\
\text { estudiados) }\end{array}$ & $\begin{array}{c}\text { Formación } \\
\text { inicial }\end{array}$ & $\begin{array}{c}\text { Dependencia } \\
\text { escuela }\end{array}$ & IVE escuela & $\begin{array}{c}\text { Condiciones } \\
\text { laborales }\end{array}$ & $\begin{array}{c}\text { Desempeño } \\
\text { escolar }\end{array}$ \\
\hline $\begin{array}{l}\text { Origen social del } \\
\text { docente }\end{array}$ & Significativo & $\begin{array}{c}\text { Significativo } \\
(1)\end{array}$ & $\begin{array}{c}\text { Significativo } \\
(1)\end{array}$ & $\begin{array}{c}\text { Significativo } \\
(2)\end{array}$ & $\begin{array}{c}\text { Significativo } \\
(3)\end{array}$ \\
\hline $\begin{array}{l}\text { Formación inicial } \\
\text { del docente }\end{array}$ & - & Significativo & Significativo & No significativo & $\begin{array}{c}\text { Significativo } \\
\text { (4) (5) }\end{array}$ \\
\hline $\begin{array}{l}\text { Dependencia } \\
\text { escuela }\end{array}$ & - & - & - & Significativo & Significativo \\
\hline $\begin{array}{l}\text { IVE escuela } \\
\begin{array}{l}\text { Condiciones } \\
\text { laborales del } \\
\text { docente }\end{array}\end{array}$ & - & - & - & Significativo & Significativo \\
\hline
\end{tabular}

1. Incluso controlando por formación inicial.

2. Incluso controlando por formación inicial y experiencia, pero no entre escuelas de igual dependencia. 3. Incluso controlando por formación inicial, experiencia y dependencia, pero no entre escuelas de igual IVE.

4. Incluso controlando por formación inicial, experiencia, dependencia e IVE.

5. Solo para el caso del desempeño en Matemáticas, no significativo al controlar por IVE.

El punto de inicio del análisis son dos asociaciones muy claras. Primero, la fuerte relación entre el origen social de los profesores y su formación inicial: es decir, la segregación de la formación docente. Segundo, la fuerte asociación entre el origen social de los docentes, tanto de la dependencia de la escuela en la que se desempeñan, como con el índice de vulnerabilidad económica de esta: es decir, la segregación del trabajo docente. Estas dos asociaciones, muy significativas, nos permiten afirmar que el fenómeno de la segregación de la carrera docente existe a través de todos sus procesos. Este es nuestro punto de partida, y desde aquí el análisis se enfocó en evaluar la magnitud y forma de los efectos que esta segregación docente pudiera tener sobre la reproducción de las desigualdades educativas entre estudiantes de distinto nivel socioeconómico. 
Cabe discutir, antes de cerrar el análisis, la diferencia entre variables mediadoras entre el origen social de los docentes y los resultados de sus pupilos, y variables de control que en cambio permiten controlar la aparición de efectos espurios -debidos a una causalidad común-.

La formación inicial de los profesores es, sin duda, una variable mediadora entre su origen social y los resultados de sus estudiantes. Es decir: se trata de un mecanismo específico mediante el cual los docentes de distinto origen social pueden adquirir habilidades diferenciadas que, luego, pueden afectar el aprendizaje de sus estudiantes. Los profesores cuyos hogares de origen tienen una posición de clase inferior, acceden a una formación de menor calidad y a menos credenciales precisamente porque comienzan su carrera desde posiciones desventajosas.

De modo similar, las condiciones laborales representan otra potencial variable mediadora. En efecto, los profesores de origen social menos privilegiado (específicamente, con menor capital cultural) acceden a escuelas municipales y (en menor medida) subvencionadas, que ofrecen condiciones laborales inferiores que las particulares pagadas, y además acceden al trabajo dentro de cada una de estas categorías en peores condiciones que sus pares. Estas deficiencias en sus condiciones de trabajo, efectivamente, reducen el logro de sus estudiantes. Tal efecto se sostiene inclusive cuando controlamos por la dependencia y nivel socioeconómico de los alumnos: es decir, se produce adicionalmente a, y en refuerzo de, las desventajas que de por sí tienen los estudiantes (de menores recursos) de los docentes de origen social menos privilegiado.

El caso de la experiencia laboral, en cambio, no puede interpretarse lógicamente como una variable mediadora: sin importar su posición social de origen, los docentes acumulan esta experiencia durante su carrera como tales.

Finalmente, la dependencia de los establecimientos y el nivel socioeconómico medio de sus estudiantes son variables que tienen una relación compleja con la segregación docente. Por un 
lado, existen clarísimas diferencias en los resultados obtenidos por las escuelas de distinta dependencia en Chile. Gran parte de esta diferencia, se ha demostrado, responde precisamente a las diferencias socioeconómicas entre sus estudiantes (Castillo, González y Puga, 2011; Puga, 2011). Existen, sin embargo, efectos residuales que son potencialmente atribuibles a las condiciones de los establecimientos ${ }^{8}$, en especial en la comparación entre colegios particulares pagados y las otras instituciones. Es factible, de acuerdo con los resultados aquí presentados, que parte de estas diferencias restantes pasen por la distinta formación inicial, así como por las distintas condiciones laborales, y en general por las mayores dificultades que enfrentan los profesores de orígenes sociales menos privilegiados: estos son, precisamente, aquellos que tienden a enseñar con la mayor frecuencia en escuelas municipales, y con mucho menor frecuencia en cambio en colegios particulares pagados.

El capital cultural incorporado de los docentes es un tercer posible mecanismo mediante el cual el origen social de los docentes podría, con independencia de la formación inicial y de las condiciones laborales, afectar los resultados académicos de sus estudiantes. Si bien la credencialización de los docentes corresponde a una forma institucionalizada de capital cultural, con este mecanismo nos referimos a la incorporación sutil y diferenciada de disposiciones específicas a partir de una posición de clase inicial. Este mecanismo es, por sus características propias, difícil de medir directamente y, por lo tanto, interpretamos sus efectos a partir de la existencia de efectos directos una vez que las variables de control y las otras variables mediadoras (mecanismos) son consideradas en los modelos.

Aclaradas estas consideraciones analíticas, revisemos los principales efectos en cuestión: los del origen social del profesor. El origen social del docente posee un efecto significativo directo sobre su formación inicial, la dependencia del establecimiento donde enseñará, la vulnerabilidad económica de sus estudiantes, y sobre las condiciones laborales a las que accede. Tiene también un fuerte efecto

8 Otras explicaciones razonables para estos efectos podrían encontrarse en el llamado efecto par (Vardardottir, 2013). 
significativo en el desempeño de sus estudiantes, aun controlando por su formación, experiencia, condiciones laborales, y dependencia de la escuela, aunque este desaparece al controlar por las condiciones socioeconómicas de los alumnos. De esto, podemos concluir que: el efecto del origen social del docente sobre los resultados educativos sin duda es relevante, $\mathrm{y}$ tiende a reforzar las desigualdades preexistentes entre estudiantes de distinto origen social; que este efecto del origen social del docente opera a través de distintos mecanismos, incluyendo una formación inicial diferenciada y el acceso a condicionales laborales diferenciadas (como efectos independientes entre sí); que entre estos mecanismos no se demuestra un mecanismo asociado al efecto directo del capital cultural de los docentes en los resultados.

Estos resultados son, por un lado, sumamente preocupantes. Más allá de cualquier política general que busque la mejoría de la formación (permanente) de los docentes, o su certificación, la segregación del sistema escolar y de la carrera docente está produciendo conjuntamente desigualdades estructuradas. Por el otro, la identificación de distintos mecanismos ilumina posibles políticas paliativas y descarta otras. La ausencia de un efecto directo del capital cultural incorporado, que bien puede responder a dos efectos opuestos de tal capital como discutimos al inicio del proyecto, nos indica que resolver el problema de la segregación docente no pasa en ningún caso por mejorar el reclutamiento de los pedagogos priorizando a quienes provengan de posiciones privilegiadas - lo que redundaría, por lo demás, en reforzar la desigualdad educativa en otros espacios-. Por el contrario, atacar este efecto reproductor de la desigualdad educativa pasa por dos esfuerzos interrelacionados. Por un lado, ocurre "sencillamente" por debilitar el ciclo de asociación entre el origen social de los docentes y el de sus pupilos: en la medida en que los docentes más privilegiados dejen de educar tendencialmente a los estudiantes más privilegiados, los efectos que observamos debieran disminuir. Por el otro, se debe atacar la segregación de la misma formación docente, y las desigualdades en términos de condiciones laborales entre las distintas modalidades escolares. Ambas opciones, si superficialmente pueden aparecer como contradictorias, son en realidad mutuamente necesarias: en tanto sigan existiendo desigualdades sociales marcadas en la sociedad chilena, y por tanto 
algunos sectores cuenten con ventajas relevantes y arbitrarias para acceder con mayor facilidad a posiciones laborales ventajosas, solo podrá romperse la asociación entre orígenes sociales del docente y sus estudiantes en la medida en que se igualen las condiciones laborales de los profesores en todo el sistema educativo, lo que implicará un importante esfuerzo de fortalecimiento de la educación pública. Y en la medida en que se avance en esta dirección, por cierto, los futuros docentes de origen social menos privilegiado habrán accedido a su vez a una formación inicial que no termine por poner a sus estudiantes en desventaja.

\section{Referencias}

Bernasconi, A. (2015). La educación superior de Chile. Transformación, desarrollo y crisis. Santiago de Chile: Ediciones Universidad Católica de Chile (Colección Estudios en educación).

Bourdieu, P. (1977). Symbolic power. Critique of anthropology, 4(13-14), 77-85.

Bourdieu, P. (1979). Distinction. A social critique of the judgment of taste. Cambridge, Mass.: Harvard University Press.

Bourdieu, P. \& Passeron, J.C. (1977). Reproduction in education, society and culture. London: Newbury Park, New Delhi: Sage Publications.

Boyd, D., Lankford, H., Loeb, S., Rockoff, J., \& Wyckoff, J. (2008). The narrowing gap in New York City teacher qualifications and its implications for student achievement in high-poverty schools. Journal of Policy Analysis Management, 27(4), 793-818.

Bravo, D., Falck, D., González, R., Manzi, J. y Peirano, C. (2008). La relación entre la evaluación docente y el rendimiento de los alumnos: evidencia para el caso de Chile. Santiago de Chile: CEPPE.

Breen, R. (1998). The persistence of class origin inequalities among school leavers in the Republic of Ireland, 1984-1993. The British Journal of Sociology, 49(2), 275-298.

Breen, R., \& Jonsson, J. O. (2005). Inequality of opportunity in comparative perspective: Recent research on educational attainment and social mobility. Annual Review of Sociology, 31(número), 223-243.

Castillo, P., González, A. y Puga, I. (2011). Gestión y efectividad en educación: evidencias comparativas entre establecimientos municipales y particulares subvencionados. Estudios Pedagógicos, 37(1), 187-206. 
Clotfelter, C., Ladd, H., \& Vigdor, J. (2007). Teacher credentials and student achievement in high school: A cross-subject analysis with student fixed effects. CALDER (Working Papers, 11).

Coleman, J. (1975). Equal educational opportunity: A definition. Oxford Review of Education 1(1), 25-29.

Goldhaber, D. \& Brewer, D. (1997): Evaluating the effect of teacher degree level on educational performance. In W. J. Fowler (Ed.), Developments in school finance (pp. 197-210). Washington, D.C.: Diane Publishing Company.

Goldthorpe, J. (2007): Cultural capital: Some critical observations. Socioligica, 2(número), 1-23.

Greenacre, M. \& Blasius, J. (Eds.) (2006). Multiple correspondence analysis and related methods. Boca Raton, Florida: Chapman \& Hall.

Grusky, D. (1983). Industrialization and the status attainment process: The thesis of industrialism reconsidered. American Sociological Review, 48(4), 494-506.

Hansen, M. \& Mastekaasa, A. (2006). Social origins and academic performance at university. European Sociological Review, 22(3), 277-291.

Jackson, M. (Ed.). (2013). Determined to succeed? Performance versus choice in educational attainment. Stanford, California: Stanford University Press (Studies in social inequality).

Jackson, M., Luijkx, R., Pollak, R., Vallet, L. A., \& van de Werfhorst, H. G. (2008). Educational fields of study and the intergenerational mobility process in comparative perspective. International Journal of Comparative Sociology, 49(4-5), 369-388.

Kivinen, O., Ahola, S., \& Hedman, J. (2001). Expanding education and improving odds? Participation in higher education in Finland in the 1980s and 1990s. Acta Sociológica, 44(2), 171-181.

Lankford, H., Loeb, S., \& Wyckoff, J. (2002). Teacher sorting and the plight of urban schools. A descriptive analysis. Educational Evaluation and Policy Analysis, 24(1), 37-62.

Lara, B., Mizala, A., \& Repetto, A. (2011). The effectiveness of private voucher education. Evidence from structural school switches. Educational Evaluation and Policy Analysis 33(2), 119-137.

Lucas, S. (2001). Effectively maintained inequality: Education transitions, track mobility, and social background effects. American Journal of Sociology, 106(6), 1642-1690. 
Marks, G. \& McMillan, J. (2003). Declining inequality? The changing impact of socio-economic background and ability on education in Australia. The British Journal of Sociology, 54(4), 453-471.

Meckes, L. y Bascopé, M. (2010). Distribución inequitativa de los nuevos profesores mejor preparados: características de origen y destino laboral de los egresados de Pedagogía Básica. Santiago de Chile: CEPPE.

Mullen, A., Goyette, K., \& Soares, J. (2003). Who goes to graduate school? Social and academic correlates of educational continuation after college. Sociology of Education, 76(2), 143-169.

Ortúzar, S., Flores, C., Milesi, C. y Cox, C. (2009). Aspectos de la formación inicial docente y su influencia en el rendimiento académico de los alumnos. Santiago de Chile: Camino al Bicentenario: Propuestas para Chile.

Parsons, T. (1970). Equality and inequality in modern society, or social stratification revisited. Sociological Inquiry, 40(2), 13-72.

Puga, I. (2011). Escuela y estratificación social en Chile. ¿Cuál es el rol de la municipalización y la educación particular subvencionada en la reproducción de la desigualdad social? Estudios Pedagógicos, 37(2), 213-232.

Rivkin, S., Hanushek, E., \& Kain, J. (2005). Teachers, Schools, and Academic Achievement. Econometrica, 73(2), 417-458.

Rockoff, J. (2004). The impact of individual teachers on student achievement: Evidence from panel data. The American Economic Review, 94(2), $247-$ 252.

Sanders, W. \& Rivers, J. C. (1996). Cumulative and residual effects of teachers on future student academic achievement. Knoxville, TN: University of Tennessee Value-Added Research and Assessment Center.

Shavit, Y. \& Blossfeld, H.P. (1993). Persistent inequality. Changing educational attainment in thirteen countries. Boulder, Colorado: Westview Press (Social inequality series).

Shavit, Y., Müller, W., \& Tame, C. (1998). From school to work. A comparative study of educational qualifications and occupational destinations. Oxford, New York: Clarendon Press; Oxford University Press.

Toledo, G., Puentes, E. y Valenzuela, P. (2010). Calidad docente y logro escolar: enfrentando el problema de ordenamiento no aleatorio entre características de profesores y alumnos (Tesis de Magíster inédita). Universidad de Chile, Santiago de Chile. 
Torche, F. (2005). Privatization reform and inequality of educational opportunity. The case of Chile. Sociology of Education, 78(4), 316-343.

Vardardottir, A. (2013). Peer effects and academic achievement. A regression discontinuity approach. Economics of Education Review, 36(número), 108-121.

Zarifa, D. (2012). Choosing fields in an expansionary era: Comparing Canada and the United States. Research in Social Stratification and Mobility, 30(3), 328-351.

Recibido: 07/09/2015

Aceptado: 20/11/2015 